\title{
Spatial regression analysis on 32 years of total column ozone data
}

\author{
J. S. Knibbe ${ }^{1,2}$, R. J. van der $A^{1}$, and A. T. J. de Laat ${ }^{1}$ \\ ${ }^{1}$ Royal Netherlands Meteorological Institute, De Bilt, the Netherlands \\ ${ }^{2}$ Faculty of Earth and Life Sciences, VU University Amsterdam, Amsterdam, the Netherlands \\ Correspondence to: J. S. Knibbe (j.s.knibbe@ vu.nl) \\ Received: 16 December 2013 - Published in Atmos. Chem. Phys. Discuss.: 27 February 2014 \\ Revised: 10 July 2014 - Accepted: 14 July 2014 - Published: 22 August 2014
}

\begin{abstract}
Multiple-regression analyses have been performed on 32 years of total ozone column data that was spatially gridded with a $1 \times 1.5^{\circ}$ resolution. The total ozone data consist of the MSR (Multi Sensor Reanalysis; 1979-2008) and 2 years of assimilated SCIAMACHY (SCanning Imaging Absorption spectroMeter for Atmospheric CHartographY) ozone data (2009-2010). The two-dimensionality in this data set allows us to perform the regressions locally and investigate spatial patterns of regression coefficients and their explanatory power. Seasonal dependencies of ozone on regressors are included in the analysis.

A new physically oriented model is developed to parameterize stratospheric ozone. Ozone variations on nonseasonal timescales are parameterized by explanatory variables describing the solar cycle, stratospheric aerosols, the quasibiennial oscillation (QBO), El Niño-Southern Oscillation (ENSO) and stratospheric alternative halogens which are parameterized by the effective equivalent stratospheric chlorine (EESC). For several explanatory variables, seasonally adjusted versions of these explanatory variables are constructed to account for the difference in their effect on ozone throughout the year. To account for seasonal variation in ozone, explanatory variables describing the polar vortex, geopotential height, potential vorticity and average day length are included. Results of this regression model are compared to that of a similar analysis based on a more commonly applied statistically oriented model.

The physically oriented model provides spatial patterns in the regression results for each explanatory variable. The EESC has a significant depleting effect on ozone at midand high latitudes, the solar cycle affects ozone positively mostly in the Southern Hemisphere, stratospheric aerosols affect ozone negatively at high northern latitudes, the effect of QBO is positive and negative in the tropics and mid- to
\end{abstract}

high latitudes, respectively, and ENSO affects ozone negatively between $30^{\circ} \mathrm{N}$ and $30^{\circ} \mathrm{S}$, particularly over the $\mathrm{Pa}-$ cific. The contribution of explanatory variables describing seasonal ozone variation is generally large at mid- to high latitudes. We observe ozone increases with potential vorticity and day length and ozone decreases with geopotential height and variable ozone effects due to the polar vortex in regions to the north and south of the polar vortices.

Recovery of ozone is identified globally. However, recovery rates and uncertainties strongly depend on choices that can be made in defining the explanatory variables. The application of several trend models, each with their own pros and cons, yields a large range of recovery rate estimates. Overall these results suggest that care has to be taken in determining ozone recovery rates, in particular for the Antarctic ozone hole.

\section{Introduction}

The observation of an ozone hole over Antarctica during the austral spring of 1985 was an important milestone for the acceptance that halogens could lead to strong regional stratospheric ozone depletion (Farman et al., 1985). The role of halogens in decreasing amounts of stratospheric ozone was later identified for other regions, such as the Arctic (Newman et al., 1997). The most important halogens leading to the decrease in ozone are chlorofluorocarbons (CFCs), hydrobromofluorocarbons (HBFCs) and hydrochlorofluorocarbons (HCFCs) (Stolarski and Cicerone, 1974; Molina et al., 1974; Newman et al., 2007; WMO, 2010). Political action was taken to ban emissions of these gasses in the Montreal protocol in 1987 and subsequent amendments. Since then, considerable research efforts have been put in monitoring the 
amount of stratospheric ozone and investigating the chemical and dynamical variables that affect ozone. In the last decade, several papers have attempted to quantify from observations the different phases of the recovery of the ozone layer (e.g., Weatherhead et al., 2006; Salby et al., 2012; Kuttipurath et al., 2013).

Various statistical analyses of long-term total ozone column records have been performed to examine the effect of external variables on total ozone using ground-based measurements (e.g., Bodeker et al., 1998; Hansen and Svenøe, 2005; Wohltmann et al., 2007; Mäder et al., 2010) and/or satellite measurements (e.g., Stolarski et al., 1991; Bodeker et al., 2001; Brunner et al., 2006). Ground-based measurements have the advantage that they often span time periods longer than those available from satellite measurements. On the other hand, satellite instruments perform measurements at a higher temporal frequency (daily) and provide global coverage. Previous statistical ozone studies using satellite measurements are based on zonally or regionally averaged ozone data and/or ozone data averaged in equivalent latitude coordinates. The latter coordinate system eliminates problems that occur when computing zonal means based on conventional coordinates, like spatiotemporal variations of the polar vortex location (Pan et al., 2012). However, regression studies have not yet analyzed total ozone in two geographical directions - latitude and longitude - to investigate the spatial variations in regressor dependencies.

Ozone regression studies typically use a number of different regressors to account for nonseasonal variation in stratospheric ozone. Before the year 2004, the long-term trend in ozone was usually modeled as a linear or piecewise linear function of time. Later, the equivalent effective stratospheric chlorine and bromine (EESC) was introduced to represent the net effect of chlorine and bromine on ozone (e.g., Jones et al., 2009; Mäder et al., 2010; Weber et al., 2011; Kuttippurath et al., 2013). Other frequently used variables to describe natural variability in ozone are the 11-year solar cycle and the quasi-biennial oscillation (QBO). Some studies have indicated that the El Niño-Southern Oscillation (ENSO) has a significant effect on stratospheric ozone in the tropics (e.g., Randel et al., 2009; Ziemke et al., 2010). In addition to these variables, the effect of stratospheric aerosols caused by the volcanic eruptions of El Chicon in 1982 and Pinatubo in 1991 are often taken into account.

Several studies have linked seasonal variations in stratospheric ozone to physical variables. At middle to high latitudes, stratospheric ozone amounts are directly coupled to the Brewer-Dobson circulation (BDC). An important driving factor of this BDC is the vertical propagation of tropospheric planetary waves, often represented by the eddy heat flux (EHF). The vertical Eliassen-Palm (EP) flux, a measure proportional to the EHF, is widely used to describe variations in the BDC (e.g., Weber et al., 2011, and references therein) and to study the evolution of tropospheric and stratospheric jet streams and their interaction with transient eddies (Vallis,
2007, chapter 12). For ozone studies the EP flux is mostly used to describe the polar stratospheric vortex (Hood and Soukharev, 2005). This vortex forms a boundary between polar and midlatitude stratospheric air and isolates polar stratospheric ozone, with important consequences for the spatial distribution and the depletion of ozone. Potential vorticity has also been reported to correlate with stratospheric ozone (Allaart et al., 1993; Riishøjgaard and Källén, 1997) as is the case for geopotential height (Ohring and Muenc, 1960; Braesicke et al., 2008).

Various methods have been applied to account for seasonality in ozone time series and the seasonal variability of external forcing on ozone throughout the year, the latter from now on referred to as "seasonal ozone dependencies". The seasonality in ozone itself and the seasonal ozone dependencies are either accounted for by expanding the regression coefficients as harmonic time series with periods of a year and half a year or by expanding the regression coefficients as twelve indicator functions, one for each month of the year. The first approach is similar to a Fourier filter on the corresponding frequencies and the latter is equivalent to performing the regressions on annual data independently for each month of the year. These different methods were discussed by Fioletov et al. (2008). However, no study has attempted to model ozone variation in terms of physical explanatory variables only.

The main aim of this study is to gain a better understanding of the physical and dynamical processes that affect the global distribution of ozone in longitude and latitude. We perform multiple regression analyses on the extended MSR data set (van der A et al., 2010) consisting of total column ozone on a $1^{\circ} \times 1.5^{\circ}$ latitude-longitude grid, spanning the time period 1979-2010. The small grid size enables us to incorporate local and regional effects in the regression models. The gridded regression results provide spatial information on ozone-regressor relations. In order to achieve physically meaningful patterns, we develop a physically oriented regression model (PHYS model), in which both the nonseasonal and seasonal ozone variabilities are described by physical explanatory variables. The seasonal ozone dependencies are examined and accounted for by specifically constructed "alternative variables". Regression results of this PHYS model are compared to regression results of a statistically oriented model (STAT model), in which the seasonal variation is parameterized as a harmonic time series with periods of a year and half a year instead of physical explanatory variables.

A second focus of this paper is on the quantification of stratospheric ozone recovery and the role of the EESC therein. We present a global trend analysis for average ozone recovery as well as specifically for the ozone hole period over Antarctica based on either EESC or piecewise linear trend (PWLT) results. We also investigate the sensitivity of these results to the "age of air" parameter in the EESC formulation and the chosen ozone recovery period as well as whether 
using the EESC is preferred over the PWLT as a measure for recovery for application in regression studies.

This paper is organized as follows. After introducing the dependent and explanatory variables in Sect. 2.1, we briefly discuss the piecewise correlation coefficients of the explanatory variables in Sect. 2.2. Section 2.3 covers the analysis of seasonal ozone dependencies required for the construction of alternative variables included in the PHYS and STAT models, which are presented in Sect. 2.4. The global spatial regression results are presented in Sect. 3.1, while detailed results for the locations Reykjavik, Bogota and the Antarctic are shown in Sect. 3.2 to represent regressions at high northern latitudes, the tropical region and high southern latitudes, respectively. Section 3.3 covers the trend analysis and the role of the EESC therein. Conclusions are presented in Sect. 4. A brief summary of conclusions in Sect. 5 ends the paper.

\section{Materials and methods}

\subsection{Data overview}

\subsubsection{MSR ozone}

For ozone, the Multi Sensor Reanalysis (MSR) data set is used (van der A et al., 2010), consisting of total column ozone data on a regular $1.5^{\circ} \times 1^{\circ}$ longitude-latitude grid. This data set is based on daily assimilated measurements from the TOMS, SBUV, GOME, SCIAMACHY, OMI and GOME-2 satellite instruments spanning the time period 1978-2008. Independent ground-based measurements from the World Ozone and Ultraviolet Data Center (WOUDC) were used for correction of biases between the different satellite measurements. Dependencies on solar zenith angle, viewing angle, time and stratospheric temperature were taken into account in the bias correction scheme. The MSR data set consists of monthly ozone averages and the standard deviations corresponding to these averaged values as a measure for the spread of ozone values within corresponding months. The MSR is extended with two years (2009 and 2010) of monthly averaged assimilated ozone measurements from SCIAMACHY on the same grid (Eskes et al., 2005). The SCIAMACHY measurements are corrected for biases in the same way as satellite measurements in the MSR. The final data set contains 32 years of gridded total column ozone data.

\subsubsection{EESC/ Long-term variability}

The long-term variability in ozone is highly correlated to the abundance of the halogens listed in the quadrennial scientific assessment of ozone depletion (WMO, 2010, and references therein). Mäder et al. (2010) suggested that the long-term ozone variability due to halogen species is best described by the EESC rather than by a piecewise linear function. To rep- resent the long-term variability as an explanatory variable, we therefore use the EESC (Newman et al., 2007). The calculation of this variable is based on the amount of bromine and chlorine atoms in various source gasses, the mixing ratio of these gasses in the stratosphere and the efficiency of these gasses in terms of halogen release. In the EESC calculation used for the global gridded regressions, the age of air and the corresponding spectrum width parameters are set to 5.5 and 2.75 years, respectively. This choice is based on our specific interest in polar stratospheric ozone depletion where the air age is assumed to be around 5.5 years. All other parameters are set at default: the WMO/UNEP 2010 scenario, the WMO 2010 release rates, inorganic fractional release rates and a bromine scaling factor of 60 . However, the use of one fixed age of air for all stratospheric ozone is a gross oversimplification. Stiller et al. (2012, their Fig. 7) show that the age of air is strongly height- and latitude-dependent. The age of air can vary from a few years in the tropics and the lowermost stratosphere at high latitudes to more than 10 years in the upper stratosphere. Hence, to test the sensitivity of our analysis for choices in the age of air we compare regression results with the EESC using air ages of 3, 4 and 5.5 years (1.5, 2 and 2.75 years for corresponding spectrum widths, respectively) and PWLT analysis for straightforward recovery rate quantification. Note that results of this study will be analyzed in order to identify the "best" regression model and trend estimator.

\subsubsection{Solar cycle}

Absorption of incoming UV radiation is a crucial mechanism for stratospheric ozone formation and affects ozone amounts. The 11-year solar cycle dominates the incoming UV radiation (Lean et al., 1989) and has been identified in many ozone records (e.g., Shindell et al., 1999). A commonly used proxy to characterize the UV radiation in ozone regression studies is the $10.7 \mathrm{~cm}$ solar flux data (NOAA), provided as a service by the National Research Council of Canada. The monthly data set is generated by daily measurements of the solar flux density at $2800 \mathrm{MHz}$, taken by radio telescopes at Ottawa (until 31 May 1991) and Penticton (from 1 July 1991). Measurements were taken at noon local time and corrected for several measurement factors to reach an accuracy of a few percent. We denote this explanatory variable with "SOLAR". See http://www.ngdc.noaa.gov/stp/solar/flux.html for the data and more information.

\subsubsection{Stratospheric aerosols}

To account for the effect of stratospheric aerosols (AERO) we use time series of stratospheric aerosols as described by Sato et al. (1993; for an update, see Bourassa et al., 2012). These data are based on measurements from the satellite instruments SAM II and SAGE as well as observations from several ground stations. This data set consists of 24 monthly 
time series corresponding to $7.5^{\circ}$ latitudinal bands of averaged amounts of stratospheric aerosols. Data are taken at a height of $20-25 \mathrm{~km}$. Aerosols taken at other stratospheric height levels are positively correlated and are, therefore, not included. For instance, the correlation coefficient between aerosols at $20-25 \mathrm{~km}$ and those at $15-20 \mathrm{~km}$ is 0.62 . The El Chicon (1982) and Pinatubo (1991) volcanic eruptions dominate the stratospheric aerosol time series.

\subsubsection{QBO}

The effect of the quasi-biennial oscillation (QBO) in easterly and westerly stratospheric winds in the tropics on stratospheric ozone is a well-established effect based on both observations and stratospheric modeling and is known to affect stratospheric ozone outside the tropics as well (McCormack et al., 2007; Witte et al., 2008; WMO 2010, chapter 2, and references therein). The QBO is represented by time series of monthly averaged wind speed measurements done by the ground station in Singapore (Baldwin et al., 2001). Time series of wind speeds measured at 30 and $10 \mathrm{hPa}$ are included to account for differences in the phase and shape of the QBO signal at these heights. We considered adding a proxy to represent the QBO at $50 \mathrm{hPa}$ but rejected this because of the high anticorrelation with the $\mathrm{QBO}$ at $10 \mathrm{hPa}$ (correlation value of $-0.69)$.

\subsubsection{El Niño-Southern Oscillation (ENSO)}

Various studies have shown that the ENSO signal affects the dynamics of the lower stratosphere, including the amount of ozone (e.g., Randel et al., 2009; Ziemke et al., 2010). The Multivariate ENSO Index (MEI) (Wolter and Timlin, 1998) is used to represent the effect of the ENSO. Sea-level pressure, zonal and meridional surface winds, sea surface temperature, surface air temperature and cloud fraction are used to calculate this index.

\subsubsection{Eliassen-Palm flux}

At mid- to high latitudes the dynamical features in the stratosphere, such as the polar vortex, are highly affected by vertical propagation of tropospheric planetary waves. The vertical Eliassen-Palm flux (EP) (Kanamitsu et al., 2002) is used as a measure of the force of this vertical propagation and the stability of these polar vortices. For the Northern and Southern Hemisphere we characterize these variables by averaging the vertical component of the EP flux at $100 \mathrm{hPa}$ over $45-75^{\circ} \mathrm{N}$ and $45-75^{\circ} \mathrm{S}$ separately and denote these variables as EP$\mathrm{N}$ and EP-S, respectively. A strong vortex isolates the polar stratospheric air and enables the formation of an ozone hole. This isolation affects the amount of ozone cumulatively in time, with larger cumulative effects in the buildup phase as compared to the rest of the year. Therefore we adjust the time series as in Brunner et al. (2006):

$x_{\mathrm{EP}}(t)=x_{\mathrm{EP}}(t-1) \cdot e^{\frac{1}{\tau}}+\tilde{x}_{\mathrm{EP}}(t)$,

where $x_{\mathrm{EP}}$ is the final EP flux time series, $\tilde{x}_{\mathrm{EP}}$ the original EP flux time series from the National Centers for Environmental Protection (NCEP) Reanalysis and $\tau$ is set to 12 months from October to March in the Northern Hemisphere (and shifted 6 months for the Southern Hemisphere) and set to 3 months for the rest of the year. Note that the EP flux is also indicative of the transport of ozone-rich air from the tropics towards midlatitudes, which should be considered in the interpretations of EP flux regression results.

\subsubsection{Geopotential height and potential vorticity}

The European Center for Medium-Range Weather Forecasts (ECMWF) reanalysis provides the geopotential height (GEO) at $500 \mathrm{hPa}$ and the potential vorticity (PV) at $150 \mathrm{hPa}$ as gridded monthly averaged fields. These variables are used as measures for the tropopause height and the mixing ratio of air between the troposphere and the stratosphere, respectively. These variables are taken at corresponding pressure levels to account for vertical propagation of tropospheric dynamics.

\subsubsection{Length of day}

Finally, the monthly average day length (DAY) is calculated for each latitude to describe the amount of exposure to solar radiation. Therefore, this variable accounts for the direct local effect of radiative variations on ozone.

Table 1 lists all variables and their sources. All time series of these explanatory variables are normalized by subtracting their mean values and dividing by their standard deviation. The normalized variables are shown in Fig. 1. We separate the explanatory variables into two groups; group A includes EESC, SOLAR, QBO, AERO and ENSO, which do not contain a seasonal component, and group B includes EP, GEO, PV and DAY, which are dominated by a seasonal component.

\subsection{Correlations between explanatory variables}

High correlation values between regression variables may cause problems for the estimation of regression coefficients as they hamper attributing variations in ozone to one particular explanatory variable both in performing the regression and interpreting results (see also Mäder et al., 2010). The correlations between the variables of group B are considered separately because GEO, PV and DAY are gridded data sets. Table 2 shows the (piecewise) correlation values of the variables of group A and EP. Due to the large correlation value (0.52) between both EP variables, we use EP-N and EP-S only in the Northern and Southern Hemisphere, respectively.

The correlations between the variables of group B are shown in Fig. 2. Most of these variables are highly correlated 
Table 1. List of variables and their sources.

\begin{tabular}{lll}
\hline Proxy & Data description & Source \\
\hline $\mathrm{O}_{3}$ & Globally gridded $\left(1 \times 1.5^{\circ}\right)$ ozone in DU & www.temis.nl/protocols/O3global.html \\
SOLAR & The $10.7 \mathrm{~cm}$ solar flux & ftp://ftp.ngdc.noaa.gov/STP/space-weather/solar-data/solar-features/ \\
EESC & Effective stratospheric chlorine and bromine & http://acd-ext.gsfc.nasa.gov/Data_services/automailer/index.html \\
deRO & $7.5^{\circ}$ zonal bands of aerosol optical thickness. & datss.nasa.gov/modelforce/strataer/tau_map.txt. \\
EP & Vertical EP flux at $100 \mathrm{hPa}$ averaged over 45-90 & www.esrl.noaa.gov/psd/data/gridded/data.ncep.reanalysis2.html \\
& degrees north $[\mathrm{N}]$ and south [S] & \\
QBO & QBO index at several pressure levels & www.geo.fu-berlin.de/en/met/ag/strat/produkte/qbo/ \\
ENSO & Multivariate El Niño-Southern Oscillation index & www.esrl.noaa.gov/psd/enso/mei \\
GEO & Geopotential height at the 500 hPa level (gridded) & http://data-portal.ecmwf.int/data/d/interim_daily/levtype=pl/ \\
PV & Potential vorticity at $150 \mathrm{hPa}$ level (gridded) & http://data-portal.ecmwf.int/data/d/interim_moda/levtype=pl/ \\
DAY & Average day length $($ gridded) & Calculated based on geometric variations \\
\hline
\end{tabular}

Table 2. Table of correlations for non-gridded proxies. Due to high correlation values between EP-N and EP-S, these variables are only used in the Northern and Southern Hemisphere, respectively. QBO10 and QBO30 represent the QBO index at 10 and at $30 \mathrm{hPa}$, respectively. Correlations greater than 0.4 are emphasized bold.

\begin{tabular}{lrrrrrrrr}
\hline Proxy & SOLAR & EESC & AERO & EP-N & EP-S & QBO10 & QBO30 & ENSO \\
\hline SOLAR & 1.00 & -0.29 & 0.18 & 0.04 & -0.09 & 0.01 & 0.03 & 0.04 \\
EESC & -0.29 & 1.00 & -0.22 & 0.02 & 0.18 & 0.03 & 0.01 & -0.12 \\
AERO & 0.18 & -0.22 & 1.00 & 0.01 & 0.11 & 0.13 & -0.13 & 0.29 \\
EP-N & 0.04 & 0.02 & 0.01 & 1.00 & $\mathbf{- 0 . 5 2}$ & 0.03 & 0.14 & -0.05 \\
EP-S & -0.09 & 0.18 & 0.11 & $-\mathbf{0 . 5 2}$ & 1.00 & 0.05 & -0.18 & 0.01 \\
QBO10 & 0.01 & 0.03 & 0.13 & 0.03 & 0.05 & 1.00 & 0.03 & -0.02 \\
QBO30 & 0.03 & 0.01 & -0.03 & 0.14 & -0.18 & 0.03 & 1.00 & 0.04 \\
ENSO & 0.04 & -0.12 & 0.29 & -0.05 & 0.01 & -0.02 & 0.04 & 1.00 \\
\hline
\end{tabular}

at middle to high latitudes. Regression runs show considerable sensitivity to these variables south of $55^{\circ} \mathrm{S}$. Among the group B variables we therefore choose to use only PV and EP south of $55^{\circ} \mathrm{S}$. The correlations between EP and DAY are nearly constant in both hemispheres, attaining correlation values of approximately -0.69 in the Northern Hemisphere and 0.17 in the Southern Hemisphere. Despite these high correlations in the Northern Hemisphere, preliminary regressions with both of these variables included and with either one of them included separately showed reasonable robustness of the obtained results up to approximately $50^{\circ} \mathrm{N}$, whereas at high latitudes the high correlations complicate interpretation of the regression results. For this reason we choose to include both EP and DAY for regressions performed in the Northern Hemisphere.

\subsection{Analysis of seasonal ozone dependencies}

Linear regressions are performed on normalized data averaged along geographical latitudes, with regression estimates expanded as 12 indicator functions, one for each month, to examine the seasonality in the regression coefficients. A linear regression model of the following form is used:

$$
\boldsymbol{Y}=\sum_{i=1}^{12} \boldsymbol{I}_{i} \cdot a_{i}+\sum_{j=1}^{m} \sum_{i=1}^{12} \boldsymbol{I}_{i} \cdot \beta_{i, j} \cdot \boldsymbol{X}_{j}+\boldsymbol{\varepsilon}
$$

where $\boldsymbol{Y}$ is a vector of monthly ozone values, $\boldsymbol{I}_{i}$ the indicator function for month $i$ of the year, $a_{i}$ the intercept coefficient of month $i$ of the year, $m$ the amount of explanatory variables, $\boldsymbol{X}_{j}$ the explanatory variable $j, \beta_{i, j}$ the regression estimate for month $i$ of variable $\boldsymbol{X}_{j}$ and $\boldsymbol{\varepsilon}$ the noise vector. The explanatory variables of group B are not included in these regressions. Since these seasonal variables are meant to parameterize seasonal variation in ozone, additionally incorporating seasonal ozone dependencies for variables of group B would create problems with respect to the few degrees of freedom in seasonal ozone variation using monthly data.

We use the least squares estimation for the regression coefficients and perform an iterative backward variable selection method similar to Mäder et al. (2007) to increase the degrees of freedom in the regressions. For each iteration the $P$ values of two-sided $T$ tests corresponding to the regression coefficients are calculated. The variable with the largest $P$ value which also exceeds a chosen significance level $\alpha$ is excluded in the following estimation step. This procedure is iterated until all $P$ values are below $\alpha$. In these regressions we set $\alpha$ at 0.1 , corresponding to a significance value of $90 \%$. This 


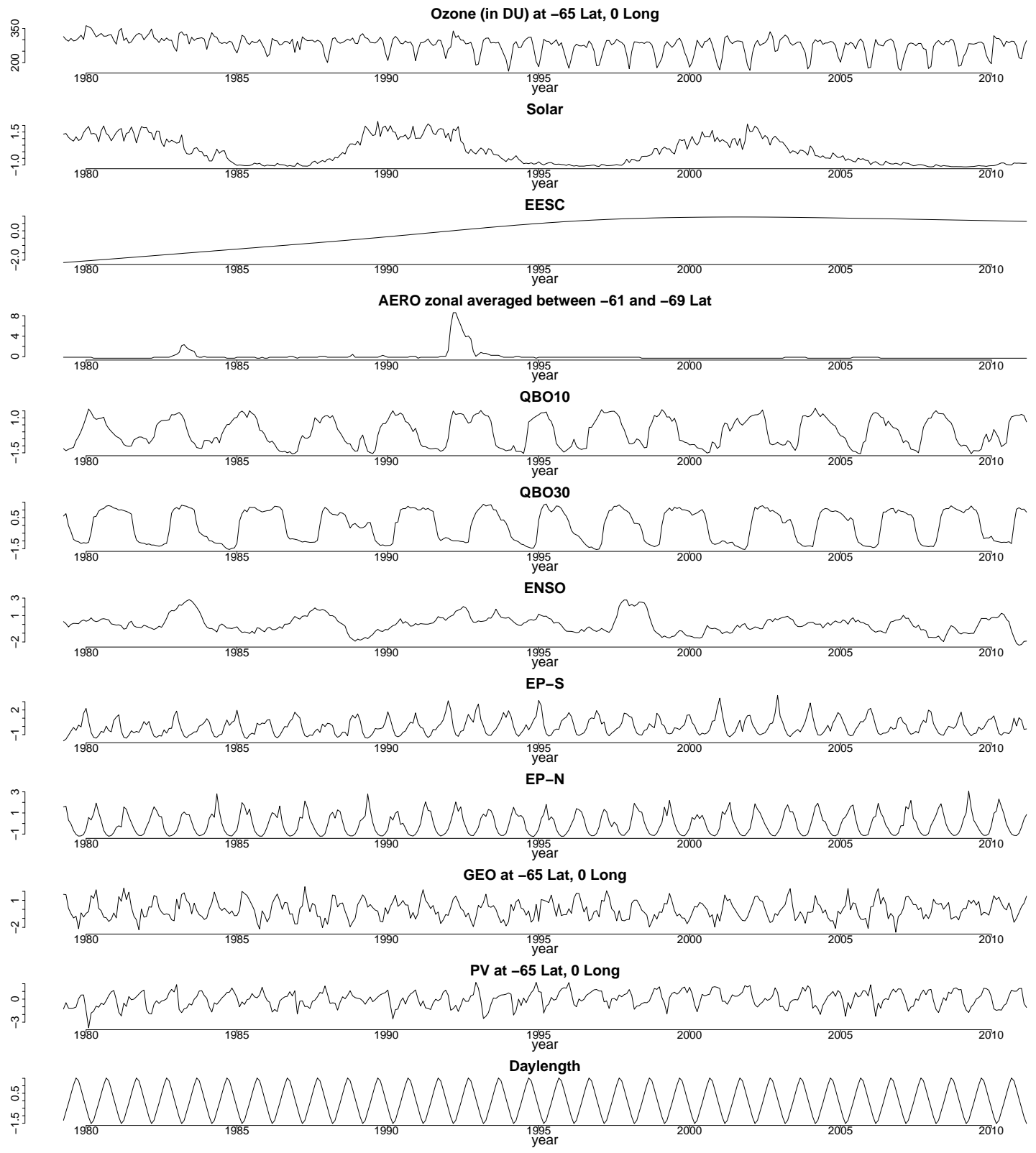

Figure 1. Time series of ozone and explanatory variables for the period $1979-2010$ at $65^{\circ} \mathrm{S}$ and $0^{\circ} \mathrm{E}$. The explanatory variables are normalized prior to plotting. QBO10 and QBO30 represent the QBO index at 10 and at $30 \mathrm{hPa}$, respectively.

rather loose significance value is chosen because at this point we are not interested in the significance of the regression estimates, but only in the seasonal patterns obtained in these regression estimates.

Figure 3 shows the regression coefficient estimates for the explanatory variables of group A. These estimates are used to determine the seasonal ozone dependencies and construct corresponding "alternative variables" to account for this effect. Except for the EESC variable, we characterize these seasonal ozone dependencies by specific harmonic functions. The seasonal ozone dependency of the EESC is con- structed using the averaged corresponding regression coefficients poleward of $65^{\circ} \mathrm{S}$.

For the $\mathrm{QBO}$ at $30 \mathrm{hPa}$ a strong seasonal variation in the estimates at midlatitudes is present. This seasonality is modeled by a cosine starting its period in March. This harmonic function follows the observed seasonality at $30^{\circ} \mathrm{S}$, and has an opposite relation to the regression estimates at $30^{\circ} \mathrm{N}$ (Fig. 3). For the QBO at $10 \mathrm{hPa}$ the seasonality in the regression estimates is described as a cosine starting its annual cycle in February. This function again aligns with the variation in 

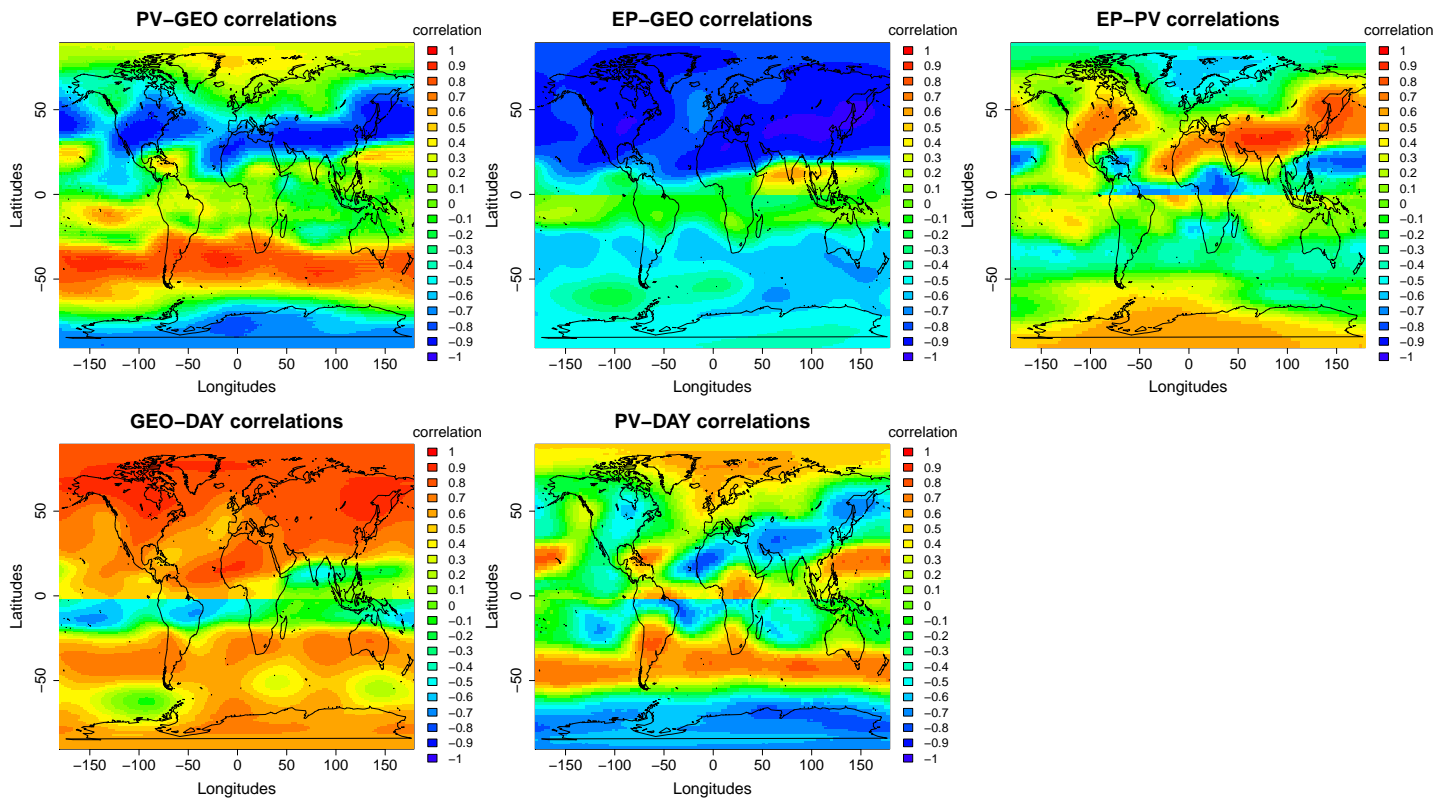

Figure 2. Correlation values between EP, GEO, PV and DAY. The correlations between EP and DAY are left out, since these values are nearly constant throughout both hemispheres $(0.17$ in the Southern Hemisphere $(\mathrm{SH})$ and -0.69 in the Northern Hemisphere (NH)).

obtained regression estimates around $30^{\circ} \mathrm{S}$ and has an opposite relation to those at around $30^{\circ} \mathrm{N}$.

Regression estimates corresponding to the ENSO variable show different values in the months from July to September in comparison to the rest of the year. This effect is modeled using a cosine with its peak in August.

The results show no convincing seasonal pattern in the estimates corresponding to the variables SOLAR and AERO. Therefore, no alternative variables are included to account for seasonal ozone dependencies of SOLAR and AERO.

The seasonal ozone dependency of EESC in polar regions does not have a harmonic shape due to the ozone hole occurring essentially from September to November. To construct the alternative variable to parameterize EESC's seasonal ozone dependency, we average the regression coefficients from the above regression in latitudes poleward of $65^{\circ} \mathrm{S}$ for each month obtaining a 32-year seasonal function $S(t)$. Assuming this seasonality in ozone dependency had marginal effects before 1979, we multiply the obtained seasonal function $S(t)$ with the increase in EESC at month $t$ with respect to its 1979 value. The above assumption is justified because the seasonal effect of ozone-depleting substances on ozone was marginal before 1980 (e.g., Li et al., 2009). Because we do not find results in Fig. 3 corresponding to the Arctic ozone hole, we do not define an alternative variable for the Arctic polar region. Year-to-year variability in Arctic ozone depletion is much larger due to a less stable Arctic stratospheric vortex (Douglass et al., 2011) such that a welldefined Arctic ozone hole is rare.

Based on the observations made above, the alternative variables QBO30_2, QBO10_2, ENSO_2 and EESC_2 are defined as follows to account for seasonally varying dependencies:

$$
\begin{aligned}
& \text { QBO30_2 }(t)=\cos (2 \pi(t-2) / 12) \cdot \mathrm{QBO} 30(t) \\
& \mathrm{QBO} 10 \_2(t)=\cos (2 \pi(t-1) / 12) \cdot \mathrm{QBO} 10(t) \\
& \text { ENSO_2 }(t)=\cos (2 \pi(t-8) / 12) \cdot \operatorname{ENSO}(t) \\
& \text { EESC_2 }(t)=(S(t)-\operatorname{mean}(S)) \cdot(\operatorname{EESC}(t)-\operatorname{EESC}(0)),
\end{aligned}
$$

where $t$ is the time in months from January 1979 and $S(t)$ is described above. These alternative variables are normalized after construction, as was done for other explanatory variables. Note that these alternative variables are not necessarily dominated by the multiplied seasonal function. This is only the case for EESC_2, due to the extremely low short-term variations in EESC. EESC_2 shows a very specific trend in this seasonality which is very different from the highly seasonal variables in group B. Therefore, the alternative variables do not interfere much with the parameterization of seasonal ozone variability in the regression models that are defined in the next section.

\subsection{Regression methods}

As mentioned before, we construct a physically oriented model (PHYS), where the nonseasonal ozone variations are accounted for by the physical explanatory variables of group A, their seasonal ozone dependencies are described by specific alternative variables and the seasonal ozone variation is described by the variables of group B. The multilinear regressions are performed using the linear model

$\boldsymbol{Y}=\boldsymbol{\beta} \cdot \mathbf{X}+\boldsymbol{\varepsilon}$, 

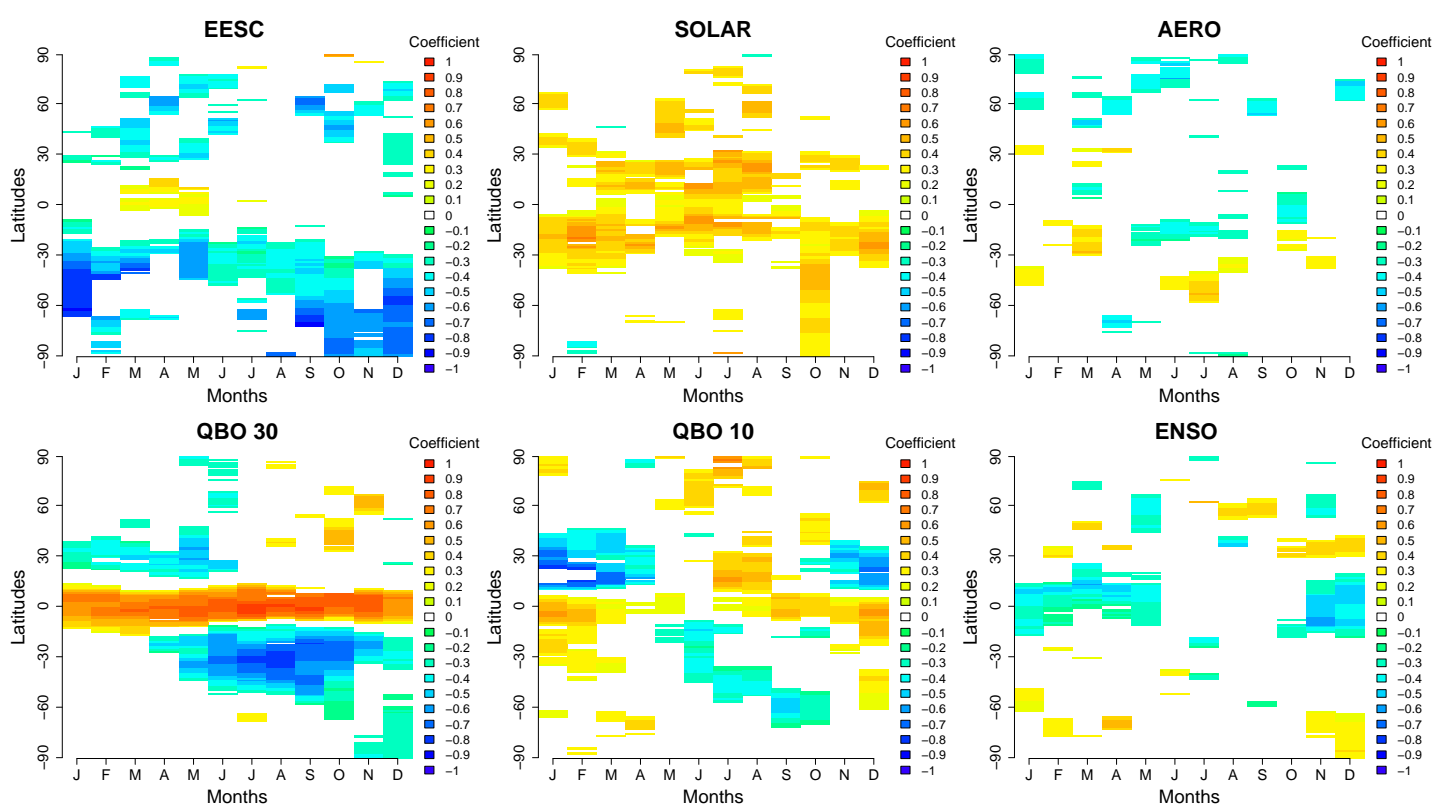

Figure 3. Monthly regression coefficient estimates for the nonseasonal explanatory variables. White regions indicate nonsignificant coefficient estimates at the $90 \%$ confidence level. QBO10 and QBO30 represent the QBO index at 10 and at $30 \mathrm{hPa}$, respectively.

where $\boldsymbol{Y}$ is the vector of monthly averaged ozone values, $\mathbf{X}$ the matrix with the explanatory variables as columns including an intercept as a column of ones, $\boldsymbol{\beta}$ the vector of regression coefficients corresponding to the columns of $\mathbf{X}$ and $\boldsymbol{\varepsilon}$ the noise vector with entries assumed to be uncorrelated and standard normal distributed. This assumption is a simplification since autocorrelation does affect the uncertainty in regression estimates. Considering that we are interested only in the geographical patterns that arise in the regression results and not the specific values of statistical errors, this simplification is justified. In the case of the trend analysis, where statistical significance has an important role, we calculate the error of the PWLT (piecewise linear trend variable, as defined below) and the EESC regression coefficients by (Press et al., 1989)

$\boldsymbol{\sigma}^{2}=\left(\mathbf{X}^{T} \mathbf{X}\right)^{-1} \cdot \frac{\sum_{t}\left((\boldsymbol{Y}-\boldsymbol{\beta} \cdot \mathbf{X})(t)^{2}\right)}{n-m} \cdot \frac{1+\varphi}{1-\varphi}$,

where $\sigma$ denotes the vector of regression errors corresponding to the regression estimates $\boldsymbol{\beta}, n$ is the length of the time series in months, $m$ is the amount of fitted parameters and $\varphi$ the estimated lag 1 autocorrelation of the residuals.

The regression coefficients are estimated using the weighted least squares method, with weights reciprocal to the variance of the monthly averaged ozone values. The backwards selection algorithm as described in Sect. 2.3 selects the explanatory variables based on significance value set to 0.01 corresponding to a significance value of $99 \%$.

For comparison, a rerun of these regressions is performed with a statistically oriented model (STAT). This model dif- fers from the above model only in the parameterization for the seasonal ozone variations. The PHYS model uses physical variables PV, GEO, EP and DAY to describe ozone variation whereas the STAT model uses harmonic time series with periods of a year and half a year for this parameterization. This method, similar to a Fourier filter on seasonal and sub-seasonal frequencies, is widely applied in previous ozone regression studies (e.g., see Fioletov et al., 2008 for an overview). Table 3 shows an overview of the incorporated explanatory variables for both the PHYS and the STAT model.

Finally, several regression runs are performed with specific focus on trend analysis and the role of EESC on ozone recovery. An important parameter in the calculation of EESC is the age of air in which the alternative halogens are contained. Differences in this parameter ultimately lead to differences in the rate of ozone recovery due to different shapes of the resulting EESC time series. We perform trend analyses using results of the PHYS model with the EESC variable at air ages 3,4 or 5.5 years or substituted by a piecewise linear function with its second linear component spanning 1997 2010, 1999-2010 or 2001-2010. The piecewise linear trend (PWLT) characterization for long-term ozone variation has the advantage that the slope in ozone recovery and ozone depletion periods can be estimated separately, whereas these slopes are proportionally fixed in the EESC curves. On the other hand the EESC parameterization yields a smooth transition from the fast early increase to the more recent gradual decrease rather than the ad hoc turn around point in the PWLT characterization. 

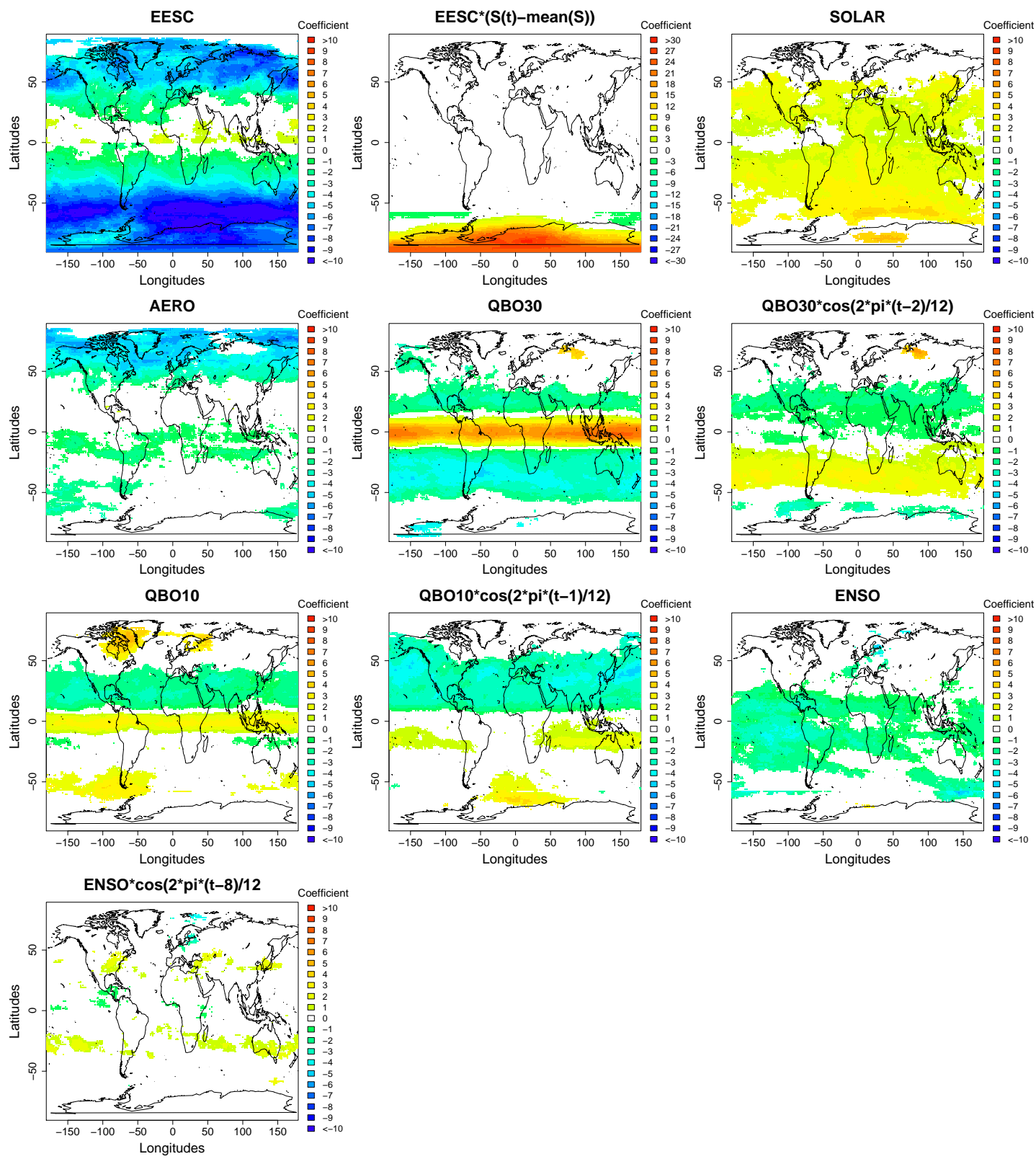

Figure 4. Regression coefficient estimates of nonseasonal variables for the PHYS model on a $1 \times 1.5^{\circ}$ grid. White regions indicate nonsignificant regression estimates at the $99 \%$ confidence level. QBO10 and QBO30 represent the QBO index at 10 and at $30 \mathrm{hPa}$, respectively. The coefficients are in DU per unit change of corresponding normalized explanatory variable. Note the different color bar range for the alternative EESC variable (a range of -30 to 30 against -10 to 10 for the other plots).

Table 3. Overview of variables included in the regression models with "group A" consisting of EESC, SOLAR, AERO, ENSO and their corresponding alternative explanatory variables, "group B" consisting of DAY, EP, PV and GEO and "Fourier terms" consisting of sines and cosines with periods of a year and half a year.

\begin{tabular}{lllll}
\hline Model variables & Intercept & Group A & Group B & Fourier terms \\
\hline PHYS model & included & included & included & not included \\
STAT model & included & included & not included & included \\
\hline
\end{tabular}



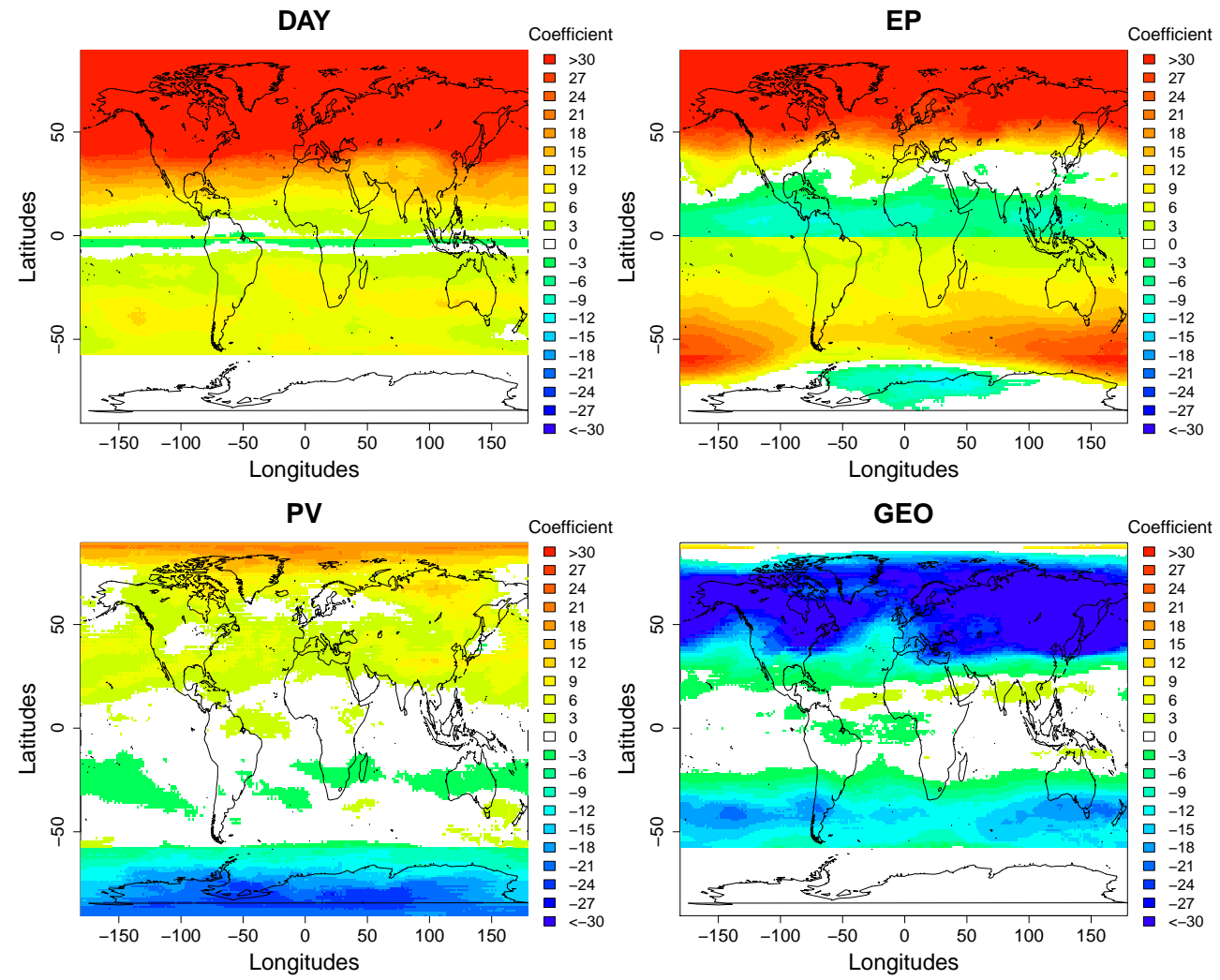

Figure 5. Regression coefficient estimates of seasonal variables for the PHYS model on a $1 \times 1.5^{\circ}$ grid. Note that, among the variables, in group B only EP and PV are included south of $55^{\circ} \mathrm{S}$ in latitude to avoid correlation problems. The coefficients are in DU per unit change of corresponding normalized explanatory variable. White regions indicate nonsignificant regression estimates at the $99 \%$ confidence level.

\section{Results}

\subsection{Multilinear regression results}

The multilinear regression results for nonseasonal variables are shown in Fig. 4. The EESC, characterizing the longterm ozone variation, has a negative effect on ozone outside the tropics with the largest effect in the Southern Hemisphere. No significant results for EESC were found in the tropical region. The negative EESC-related ozone effects at mid- to high latitudes are in agreement with the current understanding of EESC-driven ozone depletion. The ozone hole over Antarctica is parameterized by the alternative variable EESC_2, for which by construction the corresponding regression estimates are positive. Characterizing the EESC-driven occurrence of an ozone hole over Antarctica, the EESC_2 regression coefficients are large in this region. These estimates attain values indicative of ozone fluctuations up to $90 \mathrm{DU}$ in magnitude in the Antarctic in the year 2001, when the EESC attains its peak. Further quantitative analysis regarding ozone recovery rate and the role of EESC therein is performed in Sect. 3.3.

The 11-year solar cycle positively affects ozone at midand low latitudes, mainly in the Southern Hemisphere. At the Equator the regression coefficients are barely significant. The positive sign in these regression estimates is consistent with the role of UV radiation in ozone formation processes.

Stratospheric volcanic aerosols affect stratospheric ozone negatively due to catalytic ozone depletion on the surface of aerosol particles (Solomon et al., 1996). This results in negative regression estimates corresponding to this variable, mainly seen north of $45^{\circ} \mathrm{N}$.

The dependence of ozone on QBO shows clear spatial patterns. Positive regression estimates corresponding to the QBO index for the two pressure levels indicate a positive effect on ozone along the Equator. Moving towards higher latitudes the regression estimates switch to negative values at approximately $10^{\circ} \mathrm{N}$ and $10^{\circ} \mathrm{S}$. For the QBO at $30 \mathrm{hPa}$ the estimates remain negative up to $60^{\circ} \mathrm{S}$ for the Southern Hemisphere and up to the Arctic region for the Northern Hemisphere, whereas the regression estimates corresponding to the QBO at $10 \mathrm{hPa}$ switch back to positive values around $50^{\circ} \mathrm{N}$ and $50^{\circ} \mathrm{S}$.

The ENSO regression estimates show negative ozone effects of El Niño between $25^{\circ} \mathrm{S}$ and $25^{\circ} \mathrm{N}$, especially over the Pacific. The corresponding alternative variable ENSO_2 does not contribute significantly in this regression model. 

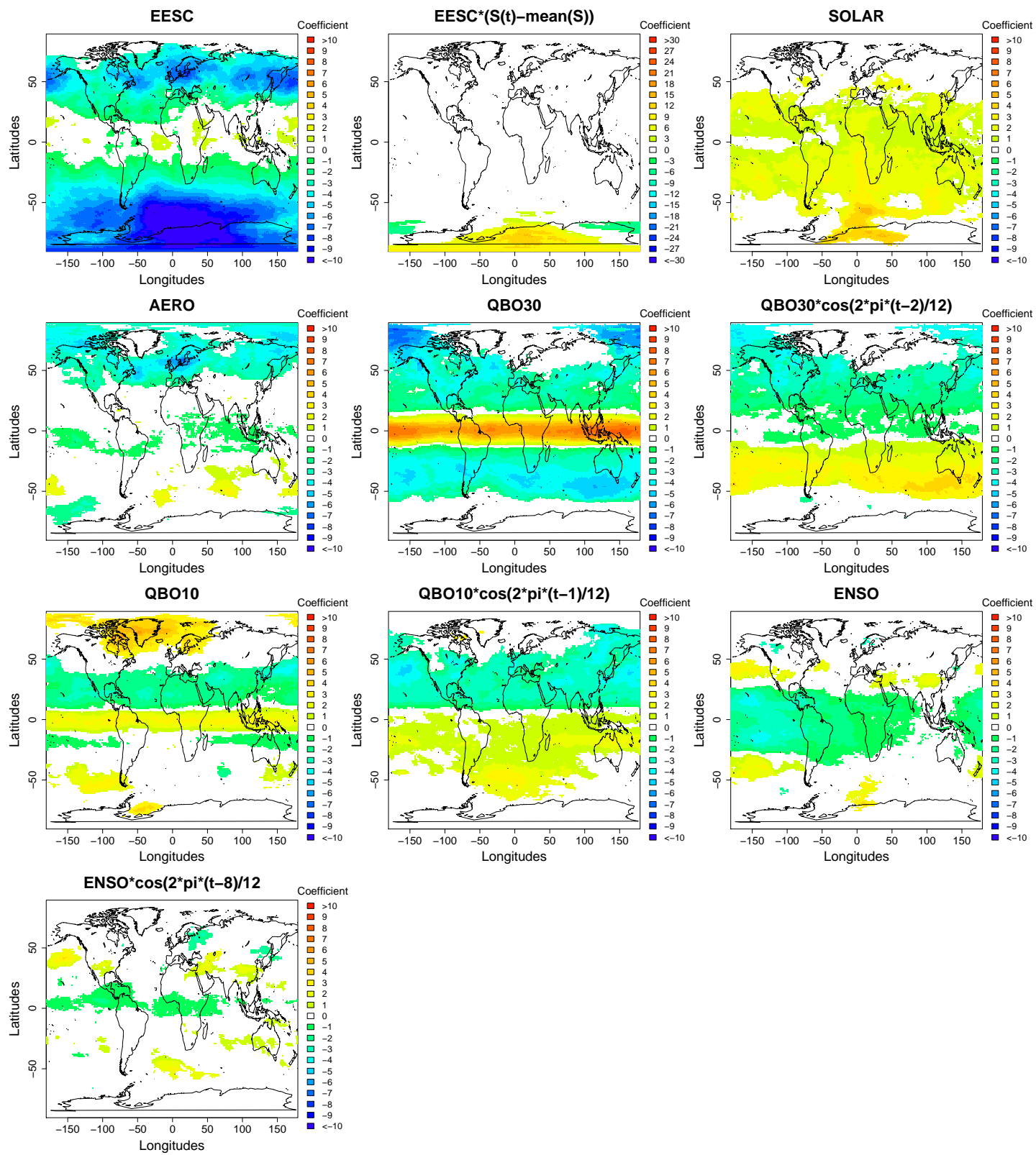

Figure 6. Regression coefficient estimates of nonseasonal variables for the STAT model on a $1 \times 1.5^{\circ}$ grid. White regions indicate nonsignificant regression estimates at the $99 \%$ confidence level. QBO10 and QBO30 represent the QBO index at 10 and at $30 \mathrm{hPa}$, respectively. The coefficients are in DU per unit change of corresponding normalized explanatory variable. Note the different color bar range for the alternative EESC variable (a range of -30 to 30 against -10 to 10 for the other plots).

Figure 5 shows the regression estimates corresponding to the seasonal variables of group B. The variable DAY - accounting for variations in radiative forcing - has the largest regression coefficients. The EP regression estimates show the different effect of EP on ozone poleward and equatorward of the polar vortex in both hemispheres. The average location of the Antarctic vortex is along a band at approximately $60^{\circ} \mathrm{S}$ where the EP regression coefficient changes sign.

The estimates corresponding to DAY are almost entirely positive throughout both hemispheres, without much spatial variability. Contrary to the DAY results, the EP results in the Northern Hemisphere show a change in sign from the tropics (negative) to higher latitudes (positive).

Significant regression results for PV are mainly found over the Arctic and Antarctic. For the Antarctic these effects also interact with the effects of DAY and EP variables on ozone where these strongly correlate to PV (see Fig. 2). The sign difference in estimates between both hemispheres is due to the sign change of potential vorticity at the Equator. As a result, the effect of vorticity at the $150 \mathrm{hPa}$ pressure level 
on ozone appears to be rather similar for both hemispheres. Ozone variations are negatively related to geopotential height (GEO) poleward of $30^{\circ} \mathrm{N}$ and around $50^{\circ} \mathrm{S}$.

One possible interpretation of the regression results for DAY and EP is that DAY represents the seasonal changes in photochemistry, whereas EP represents the seasonally varying transport processes from source regions (tropics) to sink regions (higher latitudes). As reported in Miyazaki et al. (2005), stratospheric transport from the tropics is stronger to the Northern Hemisphere is stronger compared to the Southern Hemisphere. They also note that the mean transport in the Southern Hemisphere does not extend beyond the polar vortex, whereas the eddy transport does, contrary to the Northern Hemisphere, where both mean and eddy transport contribute to transport to high latitudes. This suggests that the EP regression represents ozone transport. However, due to correlations of DAY, especially with EP, care has to be taken when interpreting these results and the EP regression estimates at high northern latitudes. South to $55^{\circ} \mathrm{S}$ the effects of DAY and PV interact because these variables are strongly correlated (see Fig. 2).

\subsection{Comparison with STAT model results}

The regression results discussed in Sect. 3.1 are compared with those from the STAT model, in which seasonal ozone variations are parameterized by harmonic time series with periods of a year and half a year, similar to a Fourier filter on the most prevalent frequencies. We compare results corresponding to the nonseasonal variables of group A and investigate whether seasonal variation is properly parameterized in the physical model by comparing the explanatory powers of both models in terms of $R^{2}$, defined as one minus the fraction of residual sum of squares divided by the sum of squares in the dependent variable. Regressions of both methods performed in Reykjavik, Iceland $\left(64^{\circ} \mathrm{N}, 23^{\circ} \mathrm{W}\right)$, Bogota, Colombia $\left(5^{\circ} \mathrm{N}, 74^{\circ} \mathrm{W}\right)$, and the Antarctic $\left(80^{\circ} \mathrm{S}, 0^{\circ} \mathrm{E}\right)$ are shown in detail to give a thorough impression of both methods at these selected sites. These three sites are considered typical for the Northern Hemisphere midlatitudes with large seasonal variation, tropics with a large influence on $\mathrm{QBO}$ and ENSO and the Antarctic vortex area.

First we compare results of the nonseasonal variables obtained by the STAT model (Fig. 6) with those obtained by the PHYS model (Fig. 4). Although nearly all of these coefficient maps show similar spatial patterns, differences are found. Small differences are in the model contribution of EESC and AERO, as the corresponding regression coefficients for these variables EESC at high northern latitudes are higher in the PHYS model than in the STAT model. More interestingly, the ozone hole characterization by EESC_2 is less obvious in the STAT model results in comparison to the PHYS model results; the reason for this difference will be clarified describing the detailed results of Antarctica. The QBO and ENSO variables, both the original and alternative variables, show latitudinal wider and stronger impact on ozone in the STAT model results than for the PHYS model results (Figs. 6 and 4, respectively). The influence of the $\mathrm{QBO}$ variables extends up to the Arctic region in the STAT model results, as compared to nearly $40^{\circ} \mathrm{N}$ for the PHYS model. Regarding the ENSO results, bands of positive regression estimates for the STAT model are present at approximately $40^{\circ} \mathrm{N}$ and $40^{\circ} \mathrm{S}$, possibly indicating an El Niño circulation pattern at midlatitudes. Furthermore ENSO_2 does indicate some seasonal effect in ENSO - ozone dependency. The corresponding spatial pattern is in agreement with results shown in Fig. 3.

Both model's performance in terms of $R^{2}$ is compared in order to investigate how well the PHYS model describes seasonal variations in ozone. Assuming the seasonal variation in ozone is completely filtered out in the STAT model using orthogonal harmonic time series, similar $R^{2}$ values for the PHYS regressions with respect to the STAT regressions are indicative of a fully physically characterized seasonal ozone component in the PHYS model. The $R^{2}$ values, as presented in Fig. 10, show similar spatial patterns for both models, except for the region north of $70^{\circ} \mathrm{N}$, where the STAT model achieves higher explained variance. The average $R^{2}$ value obtained by the PHYS model, 0.72 , is nearly at the same level as 0.79 that is (on average) achieved by the STAT model. Excluding latitudes north of $70^{\circ} \mathrm{N}$ in the averaging, these values are 0.73 and 0.78 , respectively.

Detailed results from the PHYS and STAT regressions in Reykjavik, Bogota and the Antarctic are shown in Figs. 7, 8 and 9. Corresponding regression coefficients are presented in Tables 4, 5 and 6, respectively, together with their standard errors. The "Fourier" term in these figures is defined as the sum of the harmonic components that describe seasonal ozone variation in the STAT model. For Reykjavik, QBO variables were found to be significant in the STAT model (right plot in Fig. 7) but were not found to be significant in the PHYS model (left plot in Fig. 7). Furthermore, the seasonal component in the PHYS model is described by a combination of mainly the PV, DAY and EP variables. In Bogota, only the ENSO_2 alternative variable has been excluded in the PHYS regression compared to the STAT regression (Fig. 8). The seasonal component is parameterized by only the EP and a small contribution of GEO. For the Antarctic (Fig. 9) a large difference exists in the way both methods account for the ozone hole. In the STAT regression this phenomenon is mainly described as a stationary seasonal variation using harmonic time series, with a smaller role for the constructed EESC_2, whereas the PHYS regression attributes two times more variation to EESC_2. The PV and EP variables complete the seasonal parameterization in the PHYS model.

\subsection{Ozone recovery}

An important topic of the current debate in ozone research is the detection of ozone recovery attributable to the decrease 

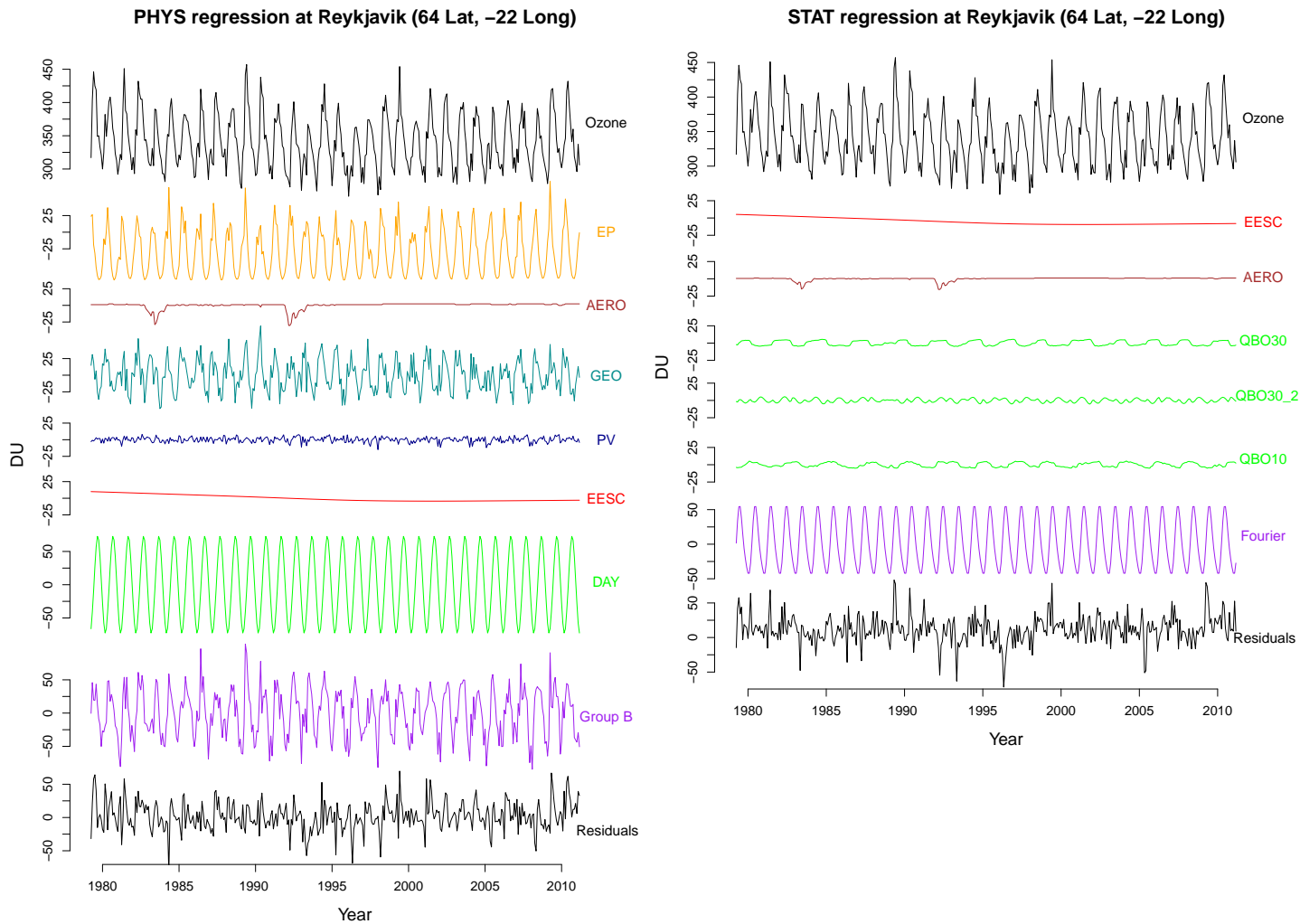

Figure 7. Results of the PHYS regression (left plot) and of the STAT regression (right plot) performed in Reykjavik, Iceland. "Fourier" is defined as the sum of the harmonic components that describe seasonal variation in ozone and the "group B" term is defined as the sum of EP, GEO, PV and DAY, describing the seasonal component according to the PHYS model. QBO10 and QBO30 represent the QBO index at 10 and at $30 \mathrm{hPa}$, respectively.
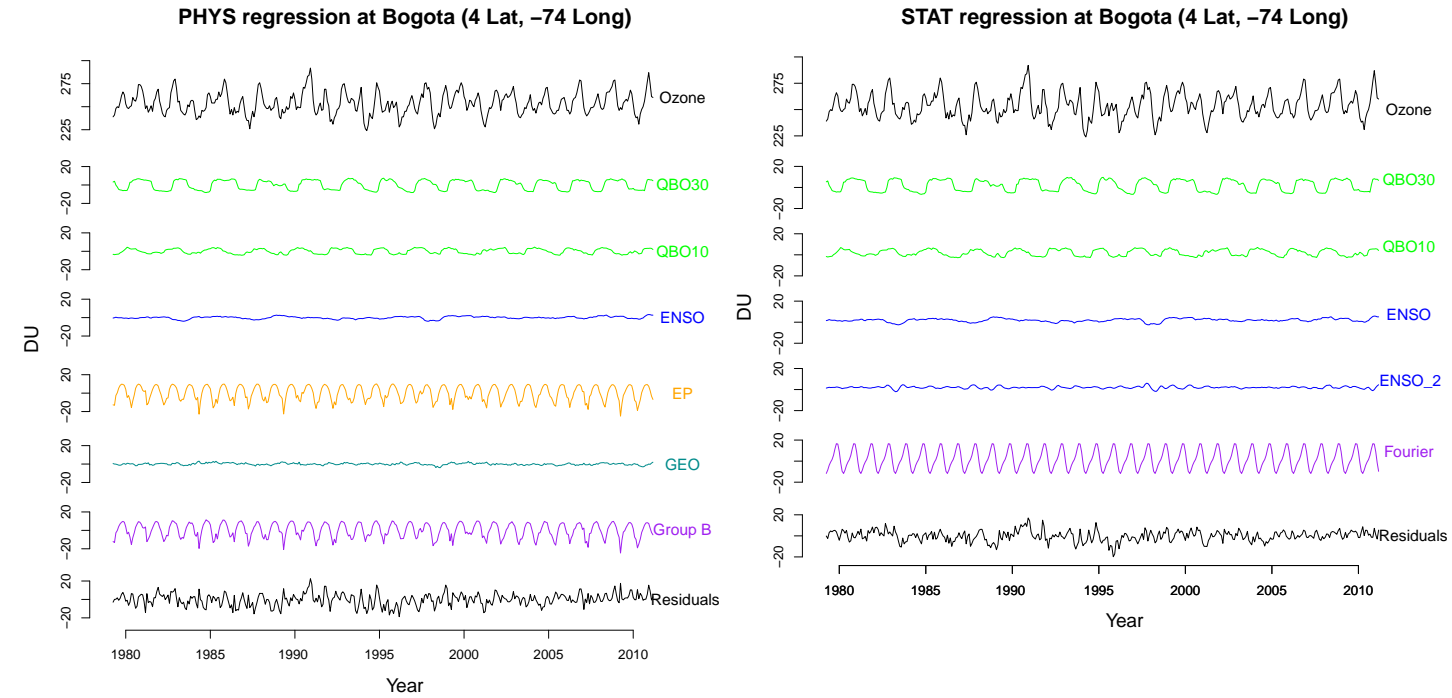

Figure 8. Results of the PHYS regression (left plot) and of the STAT regression (right plot) in Bogota, Colombia. "Fourier" is defined as the sum of the harmonic components that describe seasonal variation in ozone and the "group B" term is defined as the sum of EP and GEO, describing the seasonal component according to the PHYS model. QBO10 and QBO30 represent the QBO index at 10 and at $30 \mathrm{hPa}$, respectively. 

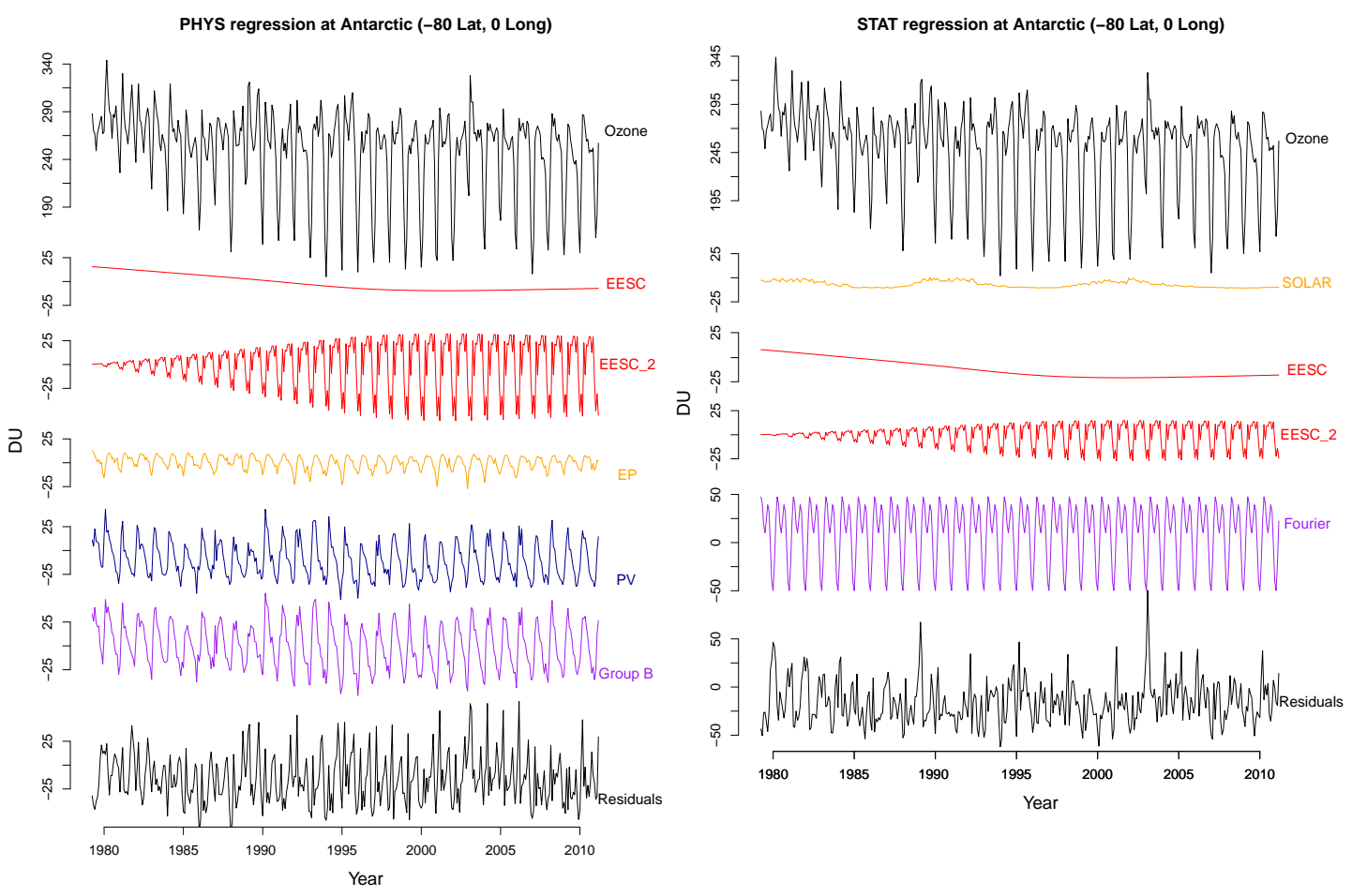

Figure 9. Results of the PHYS regression (left plot) and of the STAT regression (right plot) at $70^{\circ} \mathrm{S}, 0^{\circ} \mathrm{E}$ (Antarctica). "Fourier" is defined as the sum of the harmonic components that describe seasonal variation in ozone and the "group B" term is defined as the sum of EP and PV, describing the seasonal component according to the PHYS model.
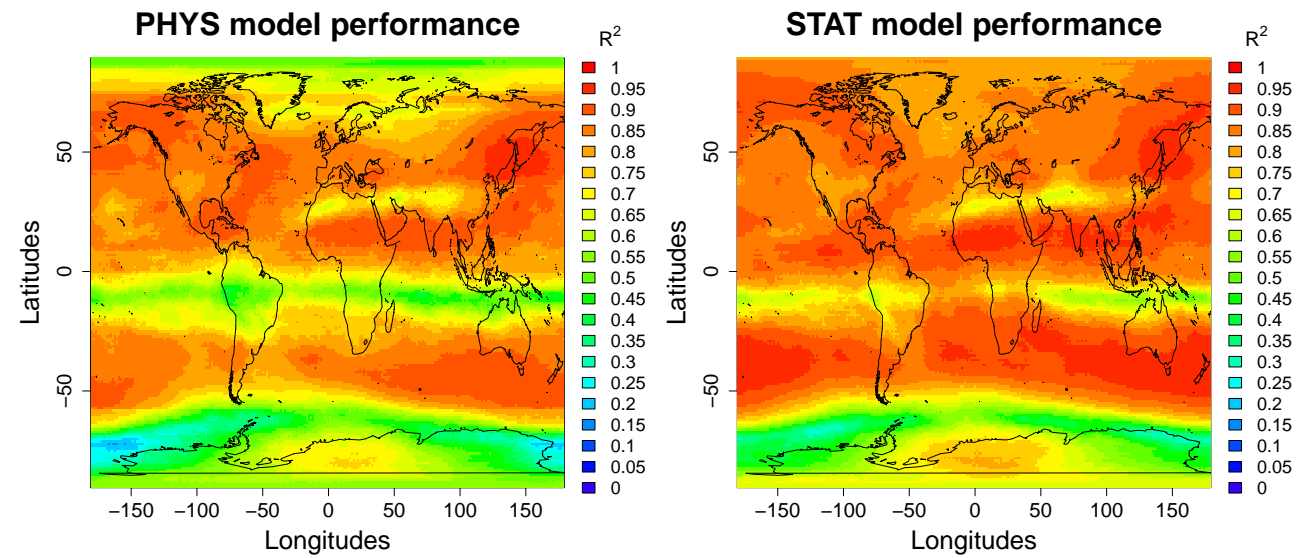

Figure 10. The performance of the PHYS regressions (left plot) and STAT regressions (right plot) in terms of $R^{2}$.

in EESC, for which a number of recent studies have relied on regression methods (Salby et al., 2011, 2012; Kuttippurath et al., 2013). In addition to the average ozone recovery, particular interest exists in the recovery of ozone over Antarctica during the ozone hole period (September-November). Both the average and the ozone hole recovery rates are quantified using EESC regression estimates from the PHYS model and by PWLT analysis. Results are significant at the $99 \%$ confidence interval.

\subsubsection{Average ozone recovery}

The first quantification for the average ozone recovery rate is based on the PHYS regression results. The average ozone recovery rate is estimated by multiplication of the EESC regression coefficient with the average rate of change in EESC since it obtained its peak value (1997, 1999 or 2001 for 3, 4 or 5.5 year air age, respectively).

As a second trend quantification method, PHYS regression runs are performed in which a piecewise linear function 

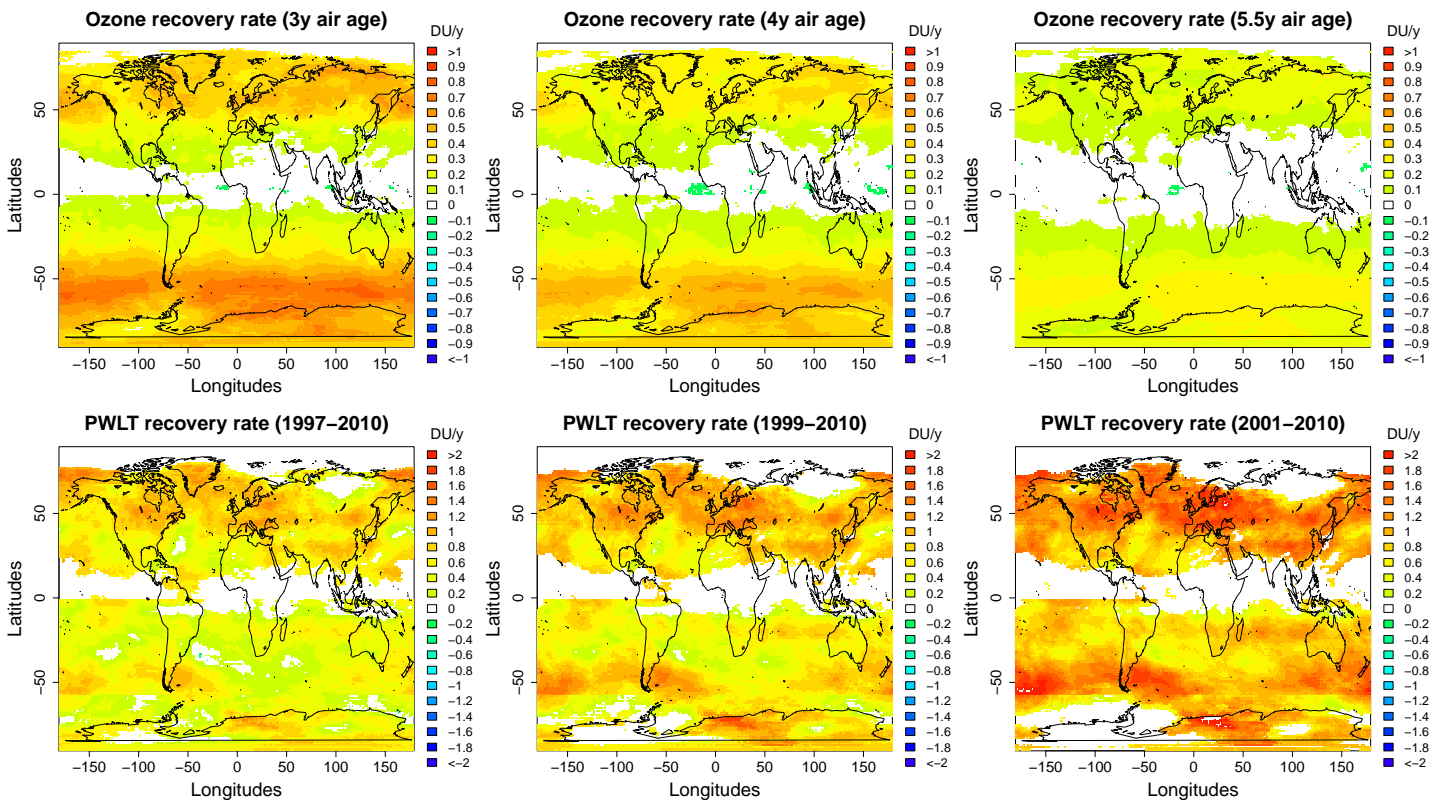

Figure 11. Ozone recovery rates based on EESC regression estimates (upper plots) or the piecewise linear function regression estimates (lower plots) using the PHYS model. Note that the color bar for the upper plots ranges from -1 to $1 \mathrm{DU} \mathrm{yr}^{-1}$, whereas for the lower plots the color bar ranges from -2 to $2 \mathrm{DU} \mathrm{yr}^{-1}$.

Table 4. Regression coefficients and standard errors of regressions in Reykjavik, Iceland. QBO10 and QBO30 represent the QBO index at 10 and at $30 \mathrm{hPa}$, respectively.

\begin{tabular}{lrr|lrr}
\hline \multicolumn{2}{c|}{ PHYS model in Reykjavik } & \multicolumn{3}{c}{ STAT model in Reykjavik } \\
Variable & Coefficient & SE & Variable & Coefficient & SE \\
\hline Intercept & 339.27 & 1.07 & Intercept & 339.7 & 0.98 \\
EP & 34.51 & 2.26 & Sine (annual cycle) & 43.7 & 1.41 \\
GEO & -23.77 & 2.22 & Cosine (annual cycle) & -20.7 & 1.29 \\
PV & 3.87 & 1.31 & Cosine (half-year cycle) & -8.5 & 1.32 \\
DAY & 51.02 & 1.84 & QBO30 & -3.6 & 1.01 \\
EESC & -4.62 & 1.03 & QBO30_2 & -2.7 & 0.97 \\
& & & QBO10 & 3.3 & 0.92 \\
& & & EESC & -4.5 & 0.90 \\
& & & AERO & -2.4 & 0.92 \\
\hline
\end{tabular}

substitutes the EESC as parameterization for long-term ozone variation. The piecewise linear function consists of a linear component from 1979 to 2010 and a component linear in either the 1997-2010, 1999-2010 or 2001-2010 time periods and 0 prior to this period. The ozone recovery rate in the latter time period is quantified by the sum of both linear components multiplied by their regression coefficients.

Results of both methods are shown in Fig. 11. We note that EESC-related ozone recovery rate estimates (the upper plots in Fig. 11) are highly dependent on the age-ofair parameter used for the EESC variable (Table 7). Assuming an air age of 3 years, the average ozone recovery rate is $0.7 \mathrm{DU} \mathrm{yr}^{-1}$ for the Southern Hemisphere (excluding the Antarctic ozone hole area) and $0.6 \mathrm{DU} \mathrm{yr}^{-1}$ for the Northern Hemisphere. For air ages of 4 and 5.5 years, these values are 0.5 and $0.3 \mathrm{DU} \mathrm{yr}^{-1}$, respectively, for the Southern Hemisphere and 0.4 and $0.2 \mathrm{DU} \mathrm{yr}^{-1}$, respectively, for the Northern Hemisphere. The 3-year air age EESC-related ozone recovery rates are found to be significant towards the tropical region, whereas the 5.5-year air age EESC-related recovery rates are found to be significant only poleward of $10^{\circ} \mathrm{S}$ and $30^{\circ} \mathrm{N}$.

The PWLT analysis provides higher ozone recovery rate estimates than the EESC. Linear recovery rate estimates spanning the 1997-2010, 1999-2010 and 2001-2010 periods are approximately $0.7,1.0$ and $1.4 \mathrm{DU} \mathrm{yr}^{-1}$, respectively, for the Southern Hemisphere and 1.0, 1.3 and 1.7 $\mathrm{DU} \mathrm{yr}^{-1}$, respectively, for the Northern Hemisphere. 
Table 5. Regression coefficients and standard errors of regressions in Bogota, Colombia. QBO10 and QBO30 represent the QBO index at 10 and at $30 \mathrm{hPa}$, respectively.

\begin{tabular}{lrl|lrr}
\hline \multicolumn{2}{c}{ PHYS model in Bogota } & \multicolumn{3}{c}{ STAT model in Bogota } \\
Variable & Coefficient & SE & Variable & Coefficient & SE \\
\hline Intercept & 254.08 & 0.34 & Intercept & 254.0 & 0.25 \\
EP & -8.10 & 0.33 & Sine (annual cycle) & -10.1 & 0.36 \\
GEO & -1.06 & 0.41 & Cosine (annual cycle) & -7.6 & 0.35 \\
ENSO & -1.35 & 0.41 & Cosine (half-year cycle) & -4.1 & 0.35 \\
QBO30 & 5.26 & 0.34 & ENSO & -1.5 & 0.27 \\
QBO10 & 2.67 & 0.34 & ENSO_2 & -1.0 & 0.26 \\
& & & QBO30 & 5.5 & 0.26 \\
& & & QBO10 & 2.9 & 0.25 \\
\hline
\end{tabular}

Table 6. Regression coefficients and standard errors of regressions at $80^{\circ} \mathrm{S}, 0^{\circ} \mathrm{E}$ (Antarctica).

\begin{tabular}{lrl|lrr}
\hline \multicolumn{2}{c}{ PHYS model in Antarctica } & \multicolumn{3}{|c}{ STAT model in Antarctica } \\
Variable & Coefficient & SE & Variable & Coefficient & SE \\
\hline Intercept & 240.6 & 1.25 & Intercept & 242.0 & 1.16 \\
EP & -6.0 & 2.08 & Sine (annual cycle) & 29.7 & 1.85 \\
PV & -20.6 & 1.86 & Sine (half-year cycle) & 22.3 & 1.67 \\
SOLAR & 3.38 & 1.3 & Cosine (annual cycle) & -8.3 & 2.23 \\
EESC & -6.07 & 1.26 & Cosine (half-year cycle) & 20.8 & 1.78 \\
EESC_2 & 24.9 & 1.53 & EESC & -9.4 & 1.16 \\
& & & EESC_2 & 11.3 & 1.79 \\
& & & SOLAR & 3.1 & 1.20 \\
\hline
\end{tabular}

Note that in particular the Southern Hemisphere recovery rates for the PWLT analysis are not or barely statistically significant.

\subsubsection{Ozone hole recovery}

A particular interest is in the recovery of Antarctic ozone in September-November, corresponding to the ozone hole period. Two methods are used to quantify the ozone recovery in this specific time period.

First, estimates of the ozone recovery rate for the ozone hole are generated by multiplication of the EESC_2 regression coefficients with the average increase in EESC_2's yearly minima per year after its largest oscillation. These recovery rates are summed with the average EESCrelated recovery rates, as calculated in the previous section (upper plots in Fig. 11). We obtain results corresponding to 3-, 4- and 5.5-year air age EESC variables. Second, a PWLT analysis is performed on yearly ozone time series of ozone averaged over September-November. This analysis is performed by again using 1997-2010, 1999-2010 or 2001-2010 as ozone recovery periods.

Ozone hole recovery rates are shown in Fig. 12 for both methods. Again we note large differences in ozone recovery rate estimates for different air age parameters and different periods for recovery rates in PWLT analysis. EESCrelated ozone hole recovery rate estimates vary between around 1.8, 1.4 and 0.9 $\mathrm{DU} \mathrm{yr}^{-1}$ for EESC variables with 3-, 4- and 5.5-year air ages, respectively. For PWLT results the estimates in the Antarctic vary between around 1.3, 2.3 and 3.1 $\mathrm{DU} \mathrm{yr}^{-1}$ for ozone recovery periods $1997-2010$, 1999-2010 and 2001-2010, respectively. The PWLT results in September-November show a larger recovery rate over Antarctica than anywhere else, related to the larger amount of ozone depletion within the Antarctic ozone hole in the September to November period. The PWLT analysis yields higher ozone recovery rates than those obtained by using the EESC curve. However, although each linear segment has been included at the $99 \%$ significance level, none of the PWLT recovery rates are statistically significant. The reason for this insignificance is that the regression coefficients of both linear segments have been summed to achieve the total recovery rate estimates. Processing the corresponding standard errors increases the final standard error.

\section{Discussion}

The spatially applied regressions provide spatial parameterization of ozone in terms of physical explanatory variables. The results show larger effects of EESC on ozone in the Southern Hemisphere than in the Northern Hemisphere and increase towards higher latitudes. This results from ozone being produced in the tropics and transported to higher latitudes 
Table 7. Ozone hole recovery rates and average ozone recovery rates for the Northern Hemisphere and the Southern Hemisphere based on EESC and PWLT regression estimates representative for the PHYS model. Values are in DU yr ${ }^{-1}$, uncertainties indicate the $2 \sigma$ (95\%) confidence intervals. The EESC-based trend estimates are determined for three different values of the EESC age of air; the PWLT estimates are provided for three different time periods.

\begin{tabular}{lcccc}
\hline Trend method & $\begin{array}{c}\text { Age of air (EESC) } \\
\text { Rec. period (PWLT) }\end{array}$ & NH & SH & $\begin{array}{c}\text { Antarctic } \\
\text { ozone hole }\end{array}$ \\
\hline EESC & 3 & $0.6 \pm 0.14$ & $0.7 \pm 0.22$ & $1.8 \pm 0.22$ \\
& 4 & $0.4 \pm 0.11$ & $0.5 \pm 0.17$ & $1.4 \pm 0.18$ \\
& 5.5 & $0.2 \pm 0.07$ & $0.3 \pm 0.13$ & $0.9 \pm 0.14$ \\
\hline PWLT & $1997-2010$ & $1.0 \pm 0.73$ & $0.7 \pm 1.59$ & $1.3 \pm 4.8$ \\
& $1999-2010$ & $1.3 \pm 0.77$ & $1.0 \pm 1.70$ & $2.3 \pm 4.6$ \\
& $2001-2010$ & $1.7 \pm 0.88$ & $1.4 \pm 1.81$ & $3.1 \pm 5.8$ \\
\hline
\end{tabular}
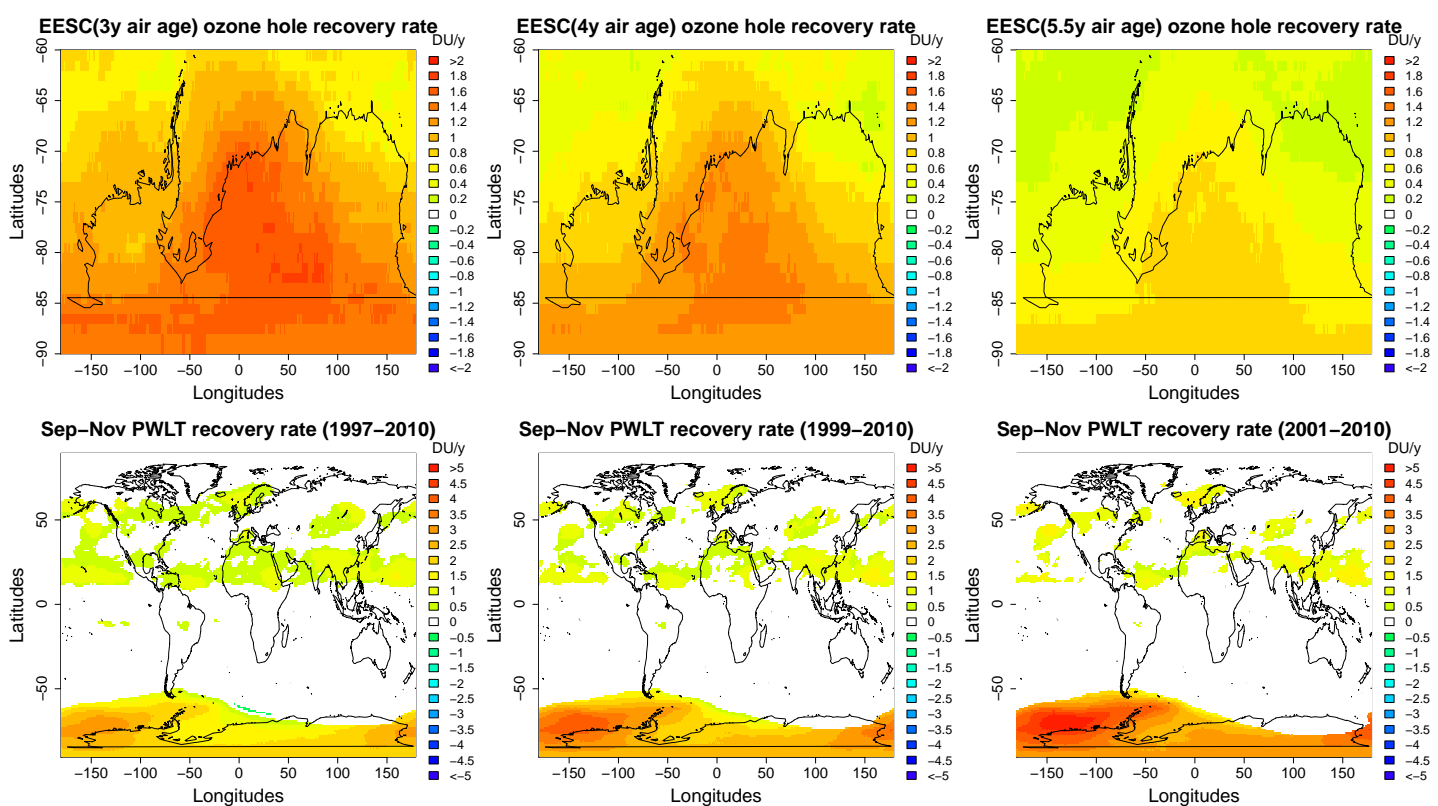

Figure 12. Ozone recovery rates based on EESC and EESC_2 regression estimates for the PHYS regressions south of $55^{\circ} \mathrm{S}$ (upper plots) and the straightforward piecewise linear regression estimates (lower plots) on ozone data averaged over September-November. Note that the color bar for the upper plots ranges from -2 to $2 \mathrm{DU} \mathrm{yr}^{-1}$, whereas for the lower plots the color bar ranges from -5 to $5 \mathrm{DU} \mathrm{yr}^{-1}$.

so that ozone at higher latitudes has been affected by ozonedepleting substances for a longer time period. A similar hemispheric asymmetry, with larger ozone influences in the Southern Hemisphere, is found in the effect induced by the solar cycle, having positive regression coefficients at midand low latitudes for both hemispheres and barely significant regression coefficients at the Equator itself. This spatially persistent but weak solar signal is consistent with results of Soukharev and Hood (2006) on the solar cycle variation in ozone and with Wohltmann et al. (2007). This solar signal extends up to more than $70^{\circ} \mathrm{S}$ between -50 and $100^{\circ}$ in longitude according to our results.

The negative effect of stratospheric aerosols particularly at high northern latitudes supports earlier findings of, for example, Solomon et al. (1996). Interestingly, the impact of vol- canic aerosols on stratospheric ozone has also been discussed extensively for the Southern Hemisphere and Antarctic based on observations (Deshler et al., 1992; Hofmann and Oltmans, 1993), model simulations (Knight et al., 1998; Rozanov et al., 2002) and regression analysis (Brunner et al., 2006; Wohltmann et al., 2007; Kuttippurath et al., 2013). Yet, in our analysis we find little evidence of Antarctic ozone being affected by volcanic aerosols. One possible explanation could be that to some extent Antarctic volcanic aerosol effects are compensated for by the EP flux and/or Antarctic Oscillation effects (see Fig. 5 of Kuttippurath et al. (2013) and Fig. 4 of Brunner et al. (2006)). Note that the Pinatubo eruption had a smaller impact on the Southern Hemisphere (Robock et al., 2007). In addition, modeling results by Knight et al. (1998) suggest that the largest Southern Hemisphere effects of the 

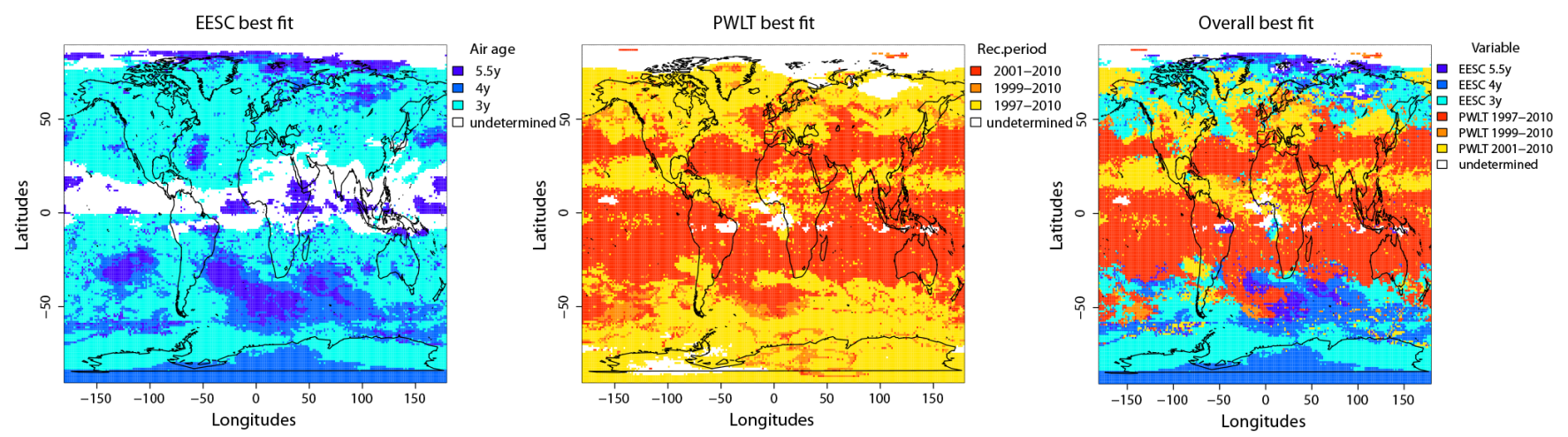

Figure 13. Comparison of $R^{2}$ values of PHYS regression runs depending on the parameterization for long-term ozone variation by the EESC with air ages of 3, 4 or 5.5 years or a piecewise linear function with the second linear component spanning 1997-2010, 1999-2010 or 2001-2010. The left plot illustrates which age-of-air parameter results in the highest $R^{2}$ value among the EESC parameterizations. The middle plot similarly illustrates which recovery period achieves the highest performance in terms of $R^{2}$. The right plot shows the result of similar comparisons among all parameterizations for long-term ozone variation. White regions indicate nonsignificant regression estimates for each of the considered explanatory variables based on a $99 \%$ significance level.

Pinatubo eruption occurred outside of the Antarctic vortex, a finding that is supported by Hofmann et al. (1997) and Solomon et al. (2005, their Figs. 3 and 13), who report only major effects of Pinatubo on ozone in the upper troposphere and lowermost stratosphere. Furthermore, results from a modeling study by Rozanov et al. (2002) only find statistically insignificant decreases in Antarctic ozone due to volcanic aerosols, suggesting other large influences on Antarctic ozone. Finally, the majority of publications identifying an effect of Pinatubo on Antarctic ozone were published in the 1990s, a period during which the role of extratropical dynamics like the EP flux on Antarctic ozone were poorly known (this started to be discussed after the year 2000).

We found broad spatial patterns concerning the QBOozone relation, which is positive at the Equator and changes to negative at around $10^{\circ} \mathrm{N}$ and $10^{\circ} \mathrm{S}$ for QBO taken at both 10 and $30 \mathrm{hPa}$. These results are in agreement with Brunner et al. (2006) and Yang and Tung (1995) on the phase propagation of the QBO signal in ozone data. The negative effects on ozone induced by ENSO events, detected between $30^{\circ} \mathrm{N}$ and $30^{\circ} \mathrm{S}$ particularly over the Pacific, are consistent with findings by Randel et al. (2009). The STAT model additionally identifies positive ENSO-related effects in small bands at $40^{\circ} \mathrm{N}$ and $40^{\circ} \mathrm{S}$. This result may indicate an ENSO effect on stratospheric ozone transport from the Equator - and the Pacific in particular - towards higher latitudes.

Interestingly, as the STAT model attributes more ozone variation to QBO and ENSO variables at higher northern latitudes as compared to PHYS model results, the PHYS results show a more persistent pattern of EESC and AERO ozone effects at high northern latitudes. The different characterization of seasonal variation in ozone in these models causes these small differences. Another difference is found in the EESC_2 results over Antarctica where a large part of ozone variations that could be interpreted as EESC-driven according to the PHYS model (Fig. 9) is accounted for by harmonic variables in the STAT model.

The important gain of the PHYS model with respect to the STAT model is the physical parameterization of seasonal ozone variation in terms of DAY, EP, PV and GEO. Except for a small band at the Equator, regression estimates show a positive effect on ozone attributed to the explanatory variable DAY, which represents the variation in local exposure to solar radiation. In the interpretation of these results, we must account for the high correlation values between EP and DAY in the Northern Hemisphere. Up to around $50^{\circ} \mathrm{N}$, the positive effect of DAY on ozone is mostly due to in situ ozone production driven by exposure to solar radiation. Towards higher latitudes the DAY regression coefficients are increasingly affected by correlation features with the EP variable complicating direct physical interpretations due to overestimation of regression coefficients. The increasingly positive EP results towards high latitudes are a result of ozone transport driven by the Brewer-Dobson circulation. In the Southern Hemisphere the EP results show different effects on ozone poleward and equatorward of the southern polar vortex, related to the separation of stratospheric air within the polar vortex. The much larger EP regression coefficients north of $40^{\circ} \mathrm{N}$ compared to the Southern Hemisphere show that eddy heat flux affects Arctic stratospheric ozone more than Antarctic stratospheric ozone. This is due to a much stronger effect of wave dynamics leading to less stability of the polar vortex in the Northern Hemisphere compared to the Southern Hemisphere (Randel et al., 2002).

Synoptic-scale weather variability, represented by PV at $150 \mathrm{hPa}$, has a positive effect on ozone, especially at high latitudes. South of $55^{\circ} \mathrm{S}$ the results of PV partly account for ozone effects of DAY, GEO and EP variables, which are correlated with PV. Finally ozone is affected negatively by high 
values of geopotential height at $500 \mathrm{hPa}$ in southern midlatitudes and northern mid- to high latitudes. The importance of synoptic-scale meteorological variability in understanding extratropical total ozone column variability has long been recognized (e.g., Harris et al., 2008; Kiesewetter et al., 2010; Rieder et al., 2010).

The explanatory power of the PHYS model approaches the explanatory power of the STAT model in regressions performed south of $70^{\circ} \mathrm{N}$ (average $R^{2}$ values of 0.73 to 0.78 for the PHYS and STAT model, respectively). Assuming the seasonal ozone component is completely accounted for in the STAT model using a Fourier filter, we conclude that the PHYS model also accounts for nearly all seasonal variation in ozone, since the models differ only in the parameterization for seasonal ozone variation. The higher performance of the STAT model as compared to the PHYS model north of $70^{\circ} \mathrm{N}$ is caused by extreme domination of stable seasonal variations in the ozone time series, which are better parameterized by the orthogonal harmonics in the STAT model. Regions where both regression models yield lower explanatory power are bands at around $55^{\circ} \mathrm{S}$ and $10^{\circ} \mathrm{S}$ and a smaller band over northern Africa stretching towards the central part of Asia. The reduced explanatory power at $55^{\circ} \mathrm{S}$ is related to the vortex edge itself. Regression studies focusing on the Antarctic ozone hole typically use either a dynamical definition like the equivalent latitude to define the vortex area or stay sufficiently far away from the vortex edge (south of $70^{\circ}$ S; e.g., Kuttipurath et al., 2013). The study of Hassler et al. (2011) shows that the shape of the Antarctic vortex has changed somewhat during the last 30 years which has consequences for analyzing Antarctic ozone. However, given that this study focuses on the global patterns of ozone variability, the use of a spatially variable definition of the vortex edge is not possible. The other bands at $10^{\circ} \mathrm{S}$ and from northern Africa to Central Asia are regions of low ozone variability. These ozone time series are dominated by white noise and are, therefore, unexplained by the regression models.

The EESC trend analysis shows significant ozone recovery in the Southern and Northern Hemisphere at a $99 \%$ significance level. Quantification of the ozone recovery rate is largely dependent on the parameterization for long-term ozone variation, consistent with findings of Kuttippurath et al. (2013). To determine which parameterization is more appropriate we compared $R^{2}$ values for PHYS regression runs of Sect. 3.3.1 in a similar manner as in the study of Mäder et al. (2010), which compares ozone regression performances using EESC or a linear function based on ozone data obtained from ground-based observations. Results, shown in Fig. 13, indicate that, among the EESC variables with 3-, 4- or 5.5year air ages, the 3-year age-of-air EESC fits the ozone data best. However, between 30 and $80^{\circ} \mathrm{S}$ there exists a large region of higher performance with the air age parameter set to 4 or 5.5 years. This may result from ozone not responding linearly to the EESC in such a way that the fit to the 3-year air age EESC is better, even if the true age of air is higher.
Looking at a similar comparison now for the PWLT fits, we note a clear distinction between high latitudes (poleward of $50^{\circ} \mathrm{N}$ and $50^{\circ} \mathrm{S}$ ), where the 1997-2010 ozone recovery period achieves high performance, and lower latitudes (equatorward of $50^{\circ} \mathrm{N}$ and $50^{\circ} \mathrm{S}$ ), where the 2001-2010 ozone recovery period fits best. This is unexpected since the higher age of air at high latitudes should result in the turnaround point occurring later in time, whereas these results indicate the converse. Finally, we see that the EESC long-term ozone parameterization yields better performance at high latitudes as compared to a PWLT function, which describes the longterm ozone variation better at lower latitudes. This result is caused by the fundamental difference of fitting a curve or a piecewise linear function. At high latitudes, the larger age of air smooths the transition from ozone depletion to ozone recovery, resulting in a better fit using the EESC curve, whereas at low latitudes the smaller age of air causes a more ad hoc ozone turnaround point, resulting in a better fit using a PWLT function.

The recovery rates and trend uncertainties thus very much depend on the chosen regression model and parameter settings of the EESC (age of air) and PWLT (recovery period). This indicates that there is a considerable amount of uncertainty present in determining the ozone recovery rate. Although these results suggest that the ozone layer is recovering globally as well as over the Antarctic, care has to be taken as many uncertainties in both the data and methodology are not taken into account. Based on these observations we conclude that ozone is recovering globally at a rate between 0.2 and $1.7 \mathrm{DU} \mathrm{yr}^{-1}$ and between 0.9 and $3.1 \mathrm{DU} \mathrm{yr}^{-1}$ for the Antarctic ozone hole period specifically. However, given the uncertainties discussed above, it is not possible to determine an appropriate trend uncertainty level, hence no statistical significance of the recovery rates can be determined.

\section{Conclusions}

This study presents the first spatial multiple regression of 32 years of total ozone column data based on assimilation of total ozone column measurements from satellites. A physically oriented regression model (PHYS) forms the basis of the study and is compared to a more statistically oriented regression model (STAT). A second aim is the detection and quantification of ozone recovery.

This first spatial regression study yields pronounced regional patterns in longitude and latitude dimensions of ozone-regressor dependencies. The effect of ENSO on ozone is mainly identified over the Pacific. We do not find clear indications of aerosol effects on ozone in the Antarctic. The effect of the 11-year solar cycle appears to be more important in the Southern Hemisphere, especially between -50 and $100^{\circ}$ in longitude, which is currently unexplained. Moreover the effects related to the southern polar vortex, clearly identified north of Antarctica, are large on total ozone columns. 
Our results broadly confirm findings from previous regression studies for local- and zonal-mean total ozone records. A clear distinction exists between the tropics and higher latitudes. In the tropics, ozone variability is dominated by the QBO whereas the 11-year solar cycle and ENSO play minor roles. Outside of the tropics, effective chlorine loading is the most important factor, and in the Northern Hemisphere volcanic aerosols also play a role. At midlatitudes, dynamical variability of the tropopause affects total ozone variability. For the Arctic, ozone variability is also determined by the EP flux, which strongly affects the vortex stability. Over the Antarctic the EP flux is much less important.

The overall explanatory power of the PHYS model approaches the explanatory power of the STAT model (average $R^{2}$ values of 0.73 and 0.78 , respectively, for regressions south of $\left.70^{\circ} \mathrm{N}\right)$. This indicates a nearly complete characterization of seasonal variation in ozone in terms of physical explanatory variables in the PHYS model. North of $70^{\circ} \mathrm{N}$ the explanatory power of the STAT model is higher than that of the PHYS model.

As for post peak-EESC ozone trends, the results of our regressions indicate that standard methods for determining trend uncertainties likely underestimate the true uncertainties in the ozone trends that can be attributed to decreasing EESC. Hence, great care has to be taken with discussing the statistical significance of these trends.

Ongoing research will focus on these unexplained variations by examining the regression residuals. In addition, effort will be put into investigating uncertainties in both regressors (what is the uncertainty in the regressors and how sensitive are the regressions to these uncertainties?) and the measurement errors of ozone. Furthermore, we also plan to perform other regression analyses to further examine the robustness of our results. Finally, robustness of the results will be tested by extending the MSR ozone record forward and backward in time.

Acknowledgements. The authors thank Mathisca de Gunst from the Free University of Amsterdam and Piet Stammes from the KNMI for their useful comments and suggestions. Furthermore, we would like to thank three anonymous reviewers for their useful suggestions on improving this manuscript.

Edited by: M. Dameris

\section{References}

Allaart, M. A. F., Kelder, H., and Heijboer, L. C.: On the relation between ozone and potential vorticity, Geophys. Res. Lett., 20, 811-814, 1993.

Baldwin, M. P., Gray, L. J., Dunkerton, T. J., Hamilton, K., Haynes, P. H., Randel, W. J., Holton, J. R., Alexander, M. J., 5 Hirota, I., Horinouchi, T., Jones, D. B. A., Kinnersley, J. S., Marquardt, C., Sato, K., and Takahashi, M. G. L.: The quasi-biennial oscillation, Rev. Geophys., 39, 179-229, 2001.
Bodeker, G. E., Boyd, I. S., and Matthews, W. A.: Trends and variability in vertical ozone and temperature profiles measured by ozonesondes at Lauder, New Zealand: 1986-1996, J. Geophys. Res., 103, 661-681, 1998.

Bodeker, G. E., Scott, J. C., Kreher, K., and Mckenzie, R. L.: Global ozone trends in potential vorticity coordinates using TOMS and GOME intercompared against the Dobson network: 1978-1998, J. Geophys. Res., 106, 29-42, 2001.

Bourassa, A. E., Robock, A., Randel, W. J., Deshler, T., Rieger, L. A., Lloyd, N. D., Llewellyn, E. J., and Degenstein, D. A.: Large volcanic aerosol load in the stratosphere linked to Asian monsoon transport, Science, 337, 78-81, 2012.

Braesicke, P., Brühl, C., Dameris, M., Deckert, R., Eyring, V., Giorgetta, M. A., Mancini, E., Manzini, E., Pitari, G., Pyle, J. A., and Steil, B.: A model intercomparison analysing the link between column ozone and geopotential height anomalies in January, Atmos. Chem. Phys., 8, 2519-2535, doi:10.5194/acp-8-2519-2008, 2008.

Brunner, D., Staehelin, J., Maeder, J. A., Wohltmann, I., and Bodeker, G. E.: Variability and trends in total and vertically resolved stratospheric ozone based on the CATO ozone data set, Atmos. Chem. Phys., 6, 4985-5008, doi:10.5194/acp-6-49852006, 2006.

de Laat, A. T. J. and van Wheele, M.: The 2010 Antarctic ozone hole: observed reduction in ozone destruction by minor sudden stratospheric warmings, Scientific Reports, 1, 38, doi:10.1038/srep00038, 2010.

Deshler, T., Adriani, A., Gobbi, G. P., Hofmann, D. J., Di Donfrancesco, G., and Johnson, B. J.: Volcanic aerosol and ozone depletion within the antarctic polar vortex during the austral spring of 1991, Geophys. Res. Lett., 19, 1819-1822, 1992.

Douglass, A., Fioletov, V., Godin-Beekman, S., Müller, R., Stolarski, R. S., Webb, A., Arola, A., Burkholder, J. B., Burrows, J. P., Chipperfield, M. P., Cordero, R., David, C., den Outer, P. N., Diaz, S. B., Flynn, L. E., Hegglin, M., Herman, J. R., Huck, P., Janjai, S., Jánosi, L. M., Krzyscin, J. W., Liu, Y., Logan, J., Matthes, K., McKenzie, R. L., Muthama, N. J., Petropavlovshikh, I., Pitts, M., Ramachandran, S., Rex, M., Salawitch, R. J., Sinnhuber, B.-M., Staehelin, J., Strahan, S., Tourpali, K., Valverde-Canossa, J., and Vigouroux, C.: Stratospheric ozone and surface ultraviolet radiation, $\mathrm{CH} 2$ in Scientific assessment of ozone depletion: 2010, WMO Glob. Ozone Res. And Mon. Proj., Report No. 52, 516 pp., Geneva, Switzerland, 2011.

Eskes, H. J., van der A, R. J., Brinksma, E. J., Veefkind, J. P., de Haan, J. F., and Valks, P. J. M.: Retrieval and validation of ozone columns derived from measurements of SCIAMACHY on Envisat, Atmos. Chem. Phys. Discuss., 5, 4429 4475, doi:10.5194/acpd-5-4429-2005, 2005.

Fioletov, V. E.: Ozone climatology, trends, and substances that control ozone, Atmos. Ocean, 46, 39-67, doi:10.3137/ao.460103, 2008.

Fortuin, J. P. F. and Kelder, H.: An ozone climatology base on ozonesonde and satellite measurements, J. Geophys. Res., 103, 31709-31734, 1998.

Frohlich, C.: Observations of irradiance variations, Space Sci. Rev., 94, 15-24, 2000. 
Hansen, G. and Svenøe, T.: Multilinear regression analysis of the 65 year Troms $\varnothing$ total ozone series, J. Geophys. Res., 110, D10103, doi:10.1029/2004JD005387, 2005.

Harris, N. R. P., Kyrö, E., Staehelin, J., Brunner, D., Andersen, S.B., Godin-Beekman, S., Dhomse, S., Hadjinicolaou, P., Hansen, G., Isaksen, I., Jrrar, A., Karpetchko, A., Kivi, R., Knudsen, B., Krizan, P., Lastovicka, J., Maeder, J., Orsolini, Y., Pyle, J. A., Rex, M., Vanicek, K., Weber, M., Wohltman, I., Zanis, P., and Zerefos, C.: Ozone trends at northern mid- and high latitudes - a European perspective, Ann. Geophys., 26, 1207-1220, doi:10.5194/angeo-26-1207-2008, 2008.

Hassler, B., Bodeker, G. E., Solomon, S., and Young, P. J.: Changes in the polar vortex: effects on Antarctic total ozone observations at various stations, Geophys. Res. Lett., 38, L01805, doi:10.1029/2010GL045542, 2011.

Hofmann, D. J. and Oltmans, S. J.: Anomalous Antarctic ozone during 1992: evidence for Pinatubo volcanic aerosol effects, J. Geophys. Res., 98, 18555-18561, doi:10.1029/93JD02092, 1993.

Hofmann, D. J., Oltmans, S. J., Harris, J. M., Johnson, B. J., and Lathrop, J. A.: Ten years of ozonesonde measurements at the south pole: implications for recovery of springtime Antarctic ozone, J. Geophys. Res., 102, 8931-8943, doi:10.1029/96JD03749, 1997.

Hood, L. L. and Soukharev, B. E.: Interannual variations of total ozone at northern midlatitudes correlated with stratospheric EP flux and potential vorticity, J. Atmos. Sci., 62, 3724-3740, doi:10.1175/JAS3559.1, 2005.

Hurwitz, M. M. and Newman, P. A.: 21st century trends in Antarctic temperature and Polar Stratospheric Cloud (PSC) area in the GEOS chemistry-climate model, J. Geophys. Res., 115, D19109, doi:10.1029/2009JD013397, 2010.

Jones, A., Urban, J., Murtagh, D. P., Eriksson, P., Brohede, S., Haley, C., Degenstein, D., Bourassa, A., von Savigny, C., Sonkaew, T., Rozanov, A., Bovensmann, H., and Burrows, J.: Evolution of stratospheric ozone and water vapour time series studied with satellite measurements, Atmos. Chem. Phys., 9, 6055-6075, doi:10.5194/acp-9-6055-2009, 2009.

Kanamitsu, M., Ebisuzaki,W.,Woollen, J., Yang, S. K., Hnilo, J. J., Fiorino, M., and Potter, G. L.: NCEP-DOE AMIP-11 REANALYSIS (R-2), B. Am. Meteorol. Soc., 83, 1631-1643, 2006.

Kiesewetter, G., Sinnhuber, B.-M., Weber, M., and Burrows, J. P.: Attribution of stratospheric ozone trends to chemistry and transport: a modelling study, Atmos. Chem. Phys., 10, 12073-2010, doi:10.5194/acp-10-12073-2010, 2010.

Knight, J. R., Austin, J., Grainger, R. G., and Lambert, A.: A threedimensional model simulation of the impact of Mt. Pinatubo aerosol on the Antarctic ozone hole, Q. J. Roy. Meteor. Soc., 124, 1527-1558, doi:10.1002/qj.49712454909, 1998.

Kuttippurath, J., Lefèvre, F., Pommereau, J.-P., Roscoe, H. K., Goutail, F., Pazmiño, A., and Shanklin, J. D.: Antarctic ozone loss in 1979-2010: first sign of ozone recovery, Atmos. Chem. Phys., 13, 1625-1635, doi:10.5194/acp-13-1625-2013, 2013.

Lean, J.: Contribution of ultraviolet irradiance variations to changes in the sun's total irradiance, Science, 244, 197-200, doi:10.1126/science.244.4901.197, 1989.

$\mathrm{Li}$, F.: Interactive comment on "stratospheric ozone in post-CFC era" by Li, F. et al., Atmos. Chem. Phys. Discuss., 8, S11413S11416, 2009.
Mäder, J. A., Staehelin, J., Brunner, D., Stahel, W. A., Wohltmann, I., and Peter, T.: Statistical modeling of total ozone: selection of appropriate explanatory variables, J. Geophys. Res., 112, D11108, doi:10.1029/2006JD007694, 2007.

Mäder, J. A., Staehelin, J., Peter, T., Brunner, D., Rieder, H. E., and Stahel, W. A.: Evidence for the effectiveness of the Montreal Protocol to protect the ozone layer, Atmos. Chem. Phys., 10, 12161-12171, doi:10.5194/acp-10-12161-2010, 2010.

McCormack, J. P., Siskind, D. E., and Hood, L. L.: Solar-QBO interaction and its impact on stratospheric ozone in a zonally averaged photochemical transport model of the middle atmosphere, $\mathrm{J}$. Geophys. Res., 112, D16109, doi:10.1029/2006JD008369, 2007.

Miyazaki, K., Iwasaki, T., Shibata, K., and Deushi, M.: Roles of transport in the seasonal variation of the total ozone amount, J. Geophys. Res., 110, D18309, doi:10.1029/2005JD005900, 2005.

Molina, M. J. and Rowland, F. S.: Stratospheric sink for chlorofluoromethanes: chlorine atom-catalysed destruction of ozone, Nature, 249, 810-812; doi:10.1038/249810a0, 1974.

Newman, P. A., Gleason, J. F., McPeters, R. D., and Stolarski, R. S.: Anomalously low ozone over the Arctic, Geophys. Res. Lett., 24, 2689-2692, 1997.

Newman, P. A., Nash, E. R., Kawa, S. R., Montzka, S. A., and Schauffler, S. M.: When will the Antarctic ozone hole recover?, Geophys. Res. Lett., 33, L12814, doi:10.1029/2005GL025232, 2006.

Ohring, G. and Muench, H. S.: relationships between ozone and meteorological parameters in the lower stratosphere, J. Meteor., 17, 195-206, doi:10.1175/15200469(1960)017<0195:RBOAMP>2.0.CO;2, 1960.

Pan, L. L., Kunz, A., Homeyer, C. R., Munchak, L. A., Kinnison, D. E., and Tilmes, S.: Commentary on using equivalent latitude in the upper troposphere and lower stratosphere, Atmos. Chem. Phys., 12, 9187-9199, doi:10.5194/acp-12-9187-2012, 2012.

Press, W. H., Flammery, B. P., Teukolski, S. A., and Vetterling, W. T. (Eds): Numerical Recipes, Cambridge University Press, Cambridge, UK, 504-508, 1989.

Randel, W. J., Wu, F., and Stolarski, R.: Changes in Column Ozone Correlated with the Stratospheric EP Flux, J. Meteorol. Soc. Jpn., 80, 849-862, 2002.

Randel, W. J., Garcia, R. R., Calvo, N., and Marsh, D.: ENSO influence on zonal mean temperature and ozone in the tropical lower stratosphere, Geophys. Res. Lett., 36, L15822, doi:10.1029/2009GL039343, 2009.

Rieder, H. E., Staehelin, J., Maeder, J. A., Peter, T., Ribatet, M., Davison, A. C., Stübi, R., Weihs, P., and Holawe, F.: Extreme events in total ozone over Arosa - Part 2: Fingerprints of atmospheric dynamics and chemistry and effects on mean values and long-term changes, Atmos. Chem. Phys., 10, 10033-10045, doi:10.5194/acp-10-10033-2010, 2010.

Riishøjgaard, J. P. and Källén, E.: On the correlation between ozone and potential vorticity for large scale Rossby waves, J. Geophys. Res., 102, 8793-8804, 1997.

Robock, A., Adams, T., Moore, M., Oman, L., and Stenchikov, G.: Southern Hemisphere atmospheric circulation effects of the 1991 Mount Pinatubo eruption, Geophys. Res. Lett., 34, L23710, doi:10.1029/2007GL031403, 2007.

Rozanov, E. V., Schlesinger, M. E., Andronova, N. G., Yang, F., Malyshev, S. L., Zubov, V. A., Egorova, T. A., and Li, B.: Climate/chemistry effects of the Pinatubo volcanic erup- 
tion simulated by the UIUC stratosphere/troposphere GCM with interactive photochemistry, J. Geophys. Res., 107, 4594, doi:10.1029/2001JD000974, 2002.

Salby, M. J., Titova, E. A., and Deschamps, L.: Changes of the Antarctic ozone hole: controlling mechanisms, seasonal predictability, and evolution, J. Geophys. Res., 117, D10111, doi:10.1029/2011JD016285, 2012.

Sato, M., Hansen, J. E., McCornick, M. P., and Pollack, J. B.: Stratospheric aerosol optical depth, 1850-1990, J. Geophys. Res., 98, 22987-22994, 1993.

Shindell, D. T., Rind, D., Balachandran, N., Lean, J., and Lonergan, P.: Solar cycle variability, ozone and climate, Science, 284, 305308, 1999.

Solomon, S., Portmann, R. W., Garcia, R. R., Thomason, L. W., Poole, L. R., and Mc-Cormick, M. P.: The role of aerosol variations in anthropogenic ozone depletion at northern midlatitudes, J. Geophys. Res., 101, 6713-6727, doi:10.1029/95JD03353, 1996.

Solomon, S., Daniel, J. S., Neely III, R. R., Vernier, J.-P., Dutton, E. G., and Thomason, L. W.: The persistently variable "background" stratospheric aerosol layer and global climate change, Science, 333, 866-870, 6044, doi:10.1126/science.1206027, 2012.

Soukharev, B. E. and Hood, L. L.: Solar cycle variation of stratospheric ozone: Multiple regression nalysis of long-term satellite data sets and comparisons with models, J. Geophys. Res., 111, D20314, doi:10.1029/2006JD007107, 2006.

Stiller, G.P., von Clarmann, T., Haenel, F., Funke, B., Glatthor, N., Grabowski, U., Kellmann, S., Kiefer, M., Linden, A.,Lossow, S., and Lopez-Puertas, M.: Observed temporal evolution of global mean age of straospheric air for 2002 to 2010 period, Atmos. Chem. Phys., 12, 3311-3331, doi:10.5194/acp-12-3311-2012, 2012.

Stolarski, R. S. and Cicerone, R. J.: Stratospheric chlorine: a possible sink for ozone, Can. J. Chem., 52, 1610, 1974.

Stolarski, R. S., Bloomfield, P., and McPeters, R. D.: Total ozone trends deduced from NIMBUS 7 TOMS data, Geophys. Res. Lett., 18, 1015-1018, 1991 .

Valis, G. K.: Atmospheric and Oceanic Fluid Dynamics: Fundamentals and Large-Scale Circulation, ISBN 0-5218-4969-1, Cambridge University Press, New York, USA, 768 pp., 2007. van der A, R. J., Allaart, M. A. F., and Eskes, H. J.: Multi sensor reanalysis of total ozone, Atmos. Chem. Phys., 10, 11277-11294, doi:10.5194/acp-10-11277-2010, 2010.

Vernier, J.-P., Thomason, L. W., Pommereau, J.-P., Bourassa, A., Pelon, J., Garnier, A., Hauchecorne, A., Blanot, L., Trepte, C., Degenstein, D., and Vargas, F.: Major influence of tropical volcanic eruptions on the stratospheric aerosol layer during the last decade, Geophys. Res. Lett., 38, L12807, doi:10.1029/2011GL047563, 2011.

Weatherhead, E. C. and Andersen, S. B.: The search for signs of recovery of the ozone layer, Nature, 441, 39-45, doi:10.1038/nature04746, 2006.

Weber, M., Dikty, S., Burrows, J. P., Garny, H., Dameris, M., Kubin, A., Abalichin, J., and Langematz, U.: The Brewer-Dobson circulation and total ozone from seasonal to decadal time scales, Atmos. Chem. Phys., 11, 11221-11235, doi:10.5194/acp-1111221-2011, 2011.

Witte, J. C., Schoeberl, M. R., Douglass, A. R., and Thompson, A. M.: The Quasi-biennial Oscillation and annual variations in tropical ozone from SHADOZ and HALOE, Atmos. Chem. Phys., 8, 3929-3936, doi:10.5194/acp-8-3929-2008, 2008.

WMO: Scientific assessment of ozone depletion: 2010, WMO Glob. Ozone Res. And Mon. Proj., Report No. 52, 516 pp., Geneva, Switzerland, 2011.

Wolter, K. and Timlim, M. S.: Monitoring ENSO in COADS with a seasonally adjusted principal component index, Proc. Of the 7th Climate Diagnostics Workshop, 01/1993, Norman, Oklahoma, 52-57, 1993.

Wolter, K. and Timlim, M. S.: Measuring the strength of ENSO events - how does 1997/98 rank?, Wheather, 53, 315-324, 1998.

Wohltmann, I., Lehmann, R., Rex, M., Brunner, D., and Mader, J. A.: A process-oriented regression model for column ozone, J. Geophys. Res., 112, D12304, doi:10.1029/2006JD007573, 2007.

Yang, H. and Tung, K. K.: On the phase propagation of extratropical ozone quasi-biennial oscillation in observational data, J. Geophys. Res., 100, 9091-9100, doi:10.1029/95JD00694, 1995.

Ziemke, J. R., Chandra, S., Oman, L. D., and Bhartia, P. K.: A new ENSO index derived from satellite measurements of column ozone, Atmos. Chem. Phys., 10, 3711-3721, doi:10.5194/acp10-3711-2010, 2010. 